\title{
Interfacial reaction issues for lead-free electronic solders
}

\author{
C. E. Ho · S. C. Yang $\cdot$ C. R. Kao
}

Published online: 22 September 2006

(C) Springer Science+Business Media, LLC 2006

\begin{abstract}
The interfacial reactions between Sn-based solders and two common substrate materials, $\mathrm{Cu}$ and $\mathrm{Ni}$, are the focuses of this paper. The reactions between Sn-based solders and $\mathrm{Cu}$ have been studied for several decades, and currently there are still many un-resolved issues. The reactions between $\mathrm{Sn}$-based solders and $\mathrm{Ni}$ are equally challenging. Recent studies further pointed out that $\mathrm{Cu}$ and $\mathrm{Ni}$ interacted strongly when they were both present in the same solder joint. While this crossinteraction introduces complications, it offers opportunities for designing better solder joints. In this study, the $\mathrm{Ni}$ effect on the reactions between solders and $\mathrm{Cu}$ is discussed first. The presence of $\mathrm{Ni}$ can in fact reduce the growth rate of $\mathrm{Cu}_{3} \mathrm{Sn}$. Excessive $\mathrm{Cu}_{3} \mathrm{Sn}$ growth can lead to the formation of Kirkendall voids, which is a leading factor responsible for poor drop test performance. The $\mathrm{Cu}$ effect on the reactions between solders and $\mathrm{Ni}$ is then covered in detail. The knowledge gained from the $\mathrm{Cu}$ and $\mathrm{Ni}$ effects is applied to explain the recently discovered intermetallic massive spalling, a process that can severely weaken a solder joint. It is pointed out that the massive spalling was caused by the
\end{abstract}

\section{E. Ho}

Department of Chemical Engineering \& Materials Science, Michigan State University, East Lansing, MI 48824, USA e-mail: ceho1975@hotmail.com

S. C. Yang

Department of Chemical \& Materials Engineering, National Central University, 320 Jhongli City, Taiwan

e-mail: tree12281228@yahoo.com.tw

C. R. Kao ( $\square)$

Department of Materials Science \& Engineering, National

Taiwan University, 106 Taipei, Taiwan

e-mail: crkao@ntu.edu.tw shifting of the equilibrium phase as more and more $\mathrm{Cu}$ was extracted out of the solder by the growing intermetallic. Lastly, the problems and opportunities brought on by the cross-interaction of $\mathrm{Cu}$ and $\mathrm{Ni}$ across a solder joint is presented.

\section{Introduction}

Soldering has been the key assembly and interconnection technology for electronic products since the dawn of the electronic age, and will remain so in the foreseeable future. Solder joints have long been recognized as the weak links in electronic products, and the reliability of each individual joint can control the overall lifespan of an electronic product. Soldering by definition involves the chemical reaction(s) between the solder and the two surfaces to be joined together [1], and consequently the importance of understanding the chemical reactions between solders and bonding surfaces cannot be overemphasized.

Figure 1 is a schematic illustration showing the key elements of the solder joints in an up-to-date electronic package. Here, the chip is connected to a ball grid array (BGA) substrate through an array of solder joints (flip-chip joints) with a diameter of around $90 \mu \mathrm{m}$. The BGA substrate is then connected to the printed circuit board (PCB) through another array of solder joints (BGA joints) that are one order of magnitude larger in diameter. This one order of magnitude difference in joint diameter actually translates into a 1,000 times difference in solder volume. Since the heat transfer during soldering is not a weak function of distance (and thus volume), the thermal histories of the flip-chip joints and the BGA joints could be very 
Fig. 1 Schematic drawing showing two types of solder joints, flip-chip joints and BGA joints, used in microelectronic packaging

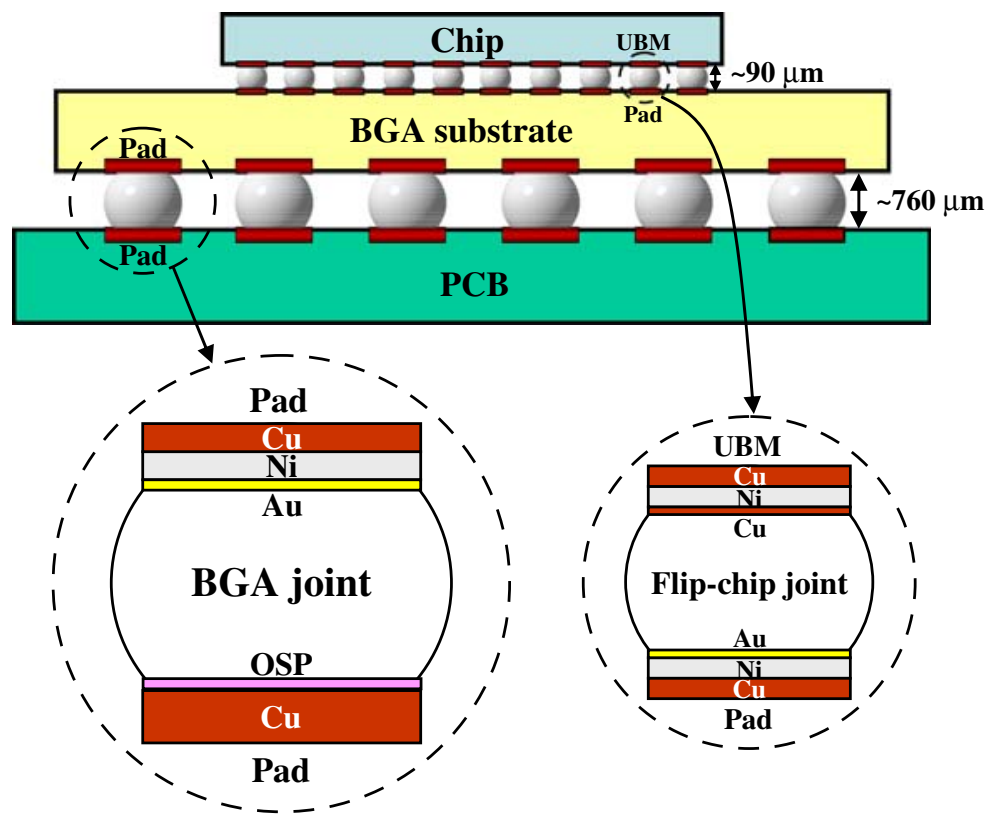

different. This difference in thermal history could in turn result in different extents of the chemical reaction, and possibly different solidification microstructures if both types of joints become molten during soldering. This effect is just one of many reasons why electronic soldering is becoming an ever more challenging technology.

Those regions on the surface of a chip that are to be in direct contact with the solders are the so-called under bump metallurgy (UBM) regions. Copper is the most popular choice for the surface layer of the UBM, mainly due to its good wetting property with solders $[2$, 3]. In Fig. 1, $\mathrm{Cu}$ is selected for illustration as the surface layer of the UBM, and the Ni layer beneath serves as the diffusion barrier layer. During assembly or normal service of the device, the $\mathrm{Cu}$ layer will be consumed completely, exposing the $\mathrm{Ni}$ layer to the solder. Those regions on the BGA and PCB substrates that are to be in contact with solders are known as the soldering pads, and the base metal of the soldering pads is always $\mathrm{Cu}$ with a few rare exceptions. The $\mathrm{Cu}$ base metal on the soldering pads of the BGA and PCB substrates has to be coated with a surface finish (or final finish) to preserve the wetting property during the storage period before assembly. Popular surface finishes include $\mathrm{Au} / \mathrm{Ni}$, immersion $\mathrm{Sn}$, immersion $\mathrm{Ag}$, and organic surface preservative (OSP). In the case of $\mathrm{Au} /$ $\mathrm{Ni}$, the $\mathrm{Au}$ layer will be dissolved into the solder rapidly during soldering [4-15], exposing the Ni layer below. In the cases of the other three surface finishes, $\mathrm{Sn}, \mathrm{Ag}$, or OSP will be dissolved into the solder (immersion $\mathrm{Sn}$ and immersion $\mathrm{Ag}$ ) or be displaced from the interface (OSP) during soldering, leaving the
$\mathrm{Cu}$ layer exposed to the solder. In Fig. 1, Au/Ni is used as the surface finish for the BGA substrate, and OSP for the PCB substrate. Summarizing all the popular material choices for the UBM and the surface finishes, one can expect that the most common material sequences across a post-assembly solder joints are, $\mathrm{Cu} /$ solder/Cu, Cu/solder/Ni, and $\mathrm{Ni} /$ solder/Ni. The Ni layer here can be deposited by electroplating, electroless plating, or sputtering. In the electroless process, a few atomic percents of $\mathrm{P}$ are often co-deposited with $\mathrm{Ni}$, and the Ni layer is customarily labeled as $\mathrm{Ni}(\mathrm{P})$. In the sputtering process, $\mathrm{V}$ is often added to the sputtering target to ease off the Ni magnetic effect to enhance the deposition rate, resulting in the co-deposition of one or two atomic percents of $\mathrm{V}$ into the Ni layer. This type of $\mathrm{Ni}$ layer is customarily labeled as $\mathrm{Ni}(\mathrm{V})$, or simply NiV. The presence of $\mathrm{P}$ or $\mathrm{V}$ in the $\mathrm{Ni}$ layer do complicate the chemical interactions between $\mathrm{Ni}$ and solders [16-38], but these reactions still share enough common features to allow a discussion of them together in this paper.

Several good review articles for electronic solders have been published in the past few years [3, 11, 29, 3944]. The intention here is not to duplicate their efforts. The focus of this paper is to review and to present original data on three key issues related to the interfacial reactions between common lead-free solders and $\mathrm{Ni}, \mathrm{Cu}$, or $\mathrm{Ni}+\mathrm{Cu}$. The first issue is about the effect of $\mathrm{Ni}$ on the interfacial reactions between solders and $\mathrm{Cu}$ (Sect. 2). Recently, the formation of Kirkendall voids during the solders/Cu reactions had been observed. These Kirkendall voids have been attributed to being the root cause for joint fracture during the drop test. 
The addition of $\mathrm{Ni}$ into solders has a strong effect on the Kirkendall voids in the solders/Cu reactions. The second issue is related to the effect of the $\mathrm{Cu}$ concentration in solders on the reactions between solders and $\mathrm{Ni}$ (Sect. 3). The problem caused by the limited supply of $\mathrm{Cu}$, known as the solder volume effect, will also be discussed. The third issue is about the cross-interaction between $\mathrm{Cu}$ and $\mathrm{Ni}$ in $\mathrm{Cu} /$ solder/Ni sandwich joints (Sect. 4).

\section{Effects of Ni on the reactions between Sn-based solders and $\mathrm{Cu}$}

Among all the binary systems, the $\mathrm{Cu}-\mathrm{Sn}$ is the most important one in many respects. Historically, $\mathrm{Cu}-\mathrm{Sn}$ alloys have been used as bronze for 6,000 years, and soldering based on the $\mathrm{Cu}-\mathrm{Sn}$ reaction for Jewellery making has a history of over 4,000 years. Today, $\mathrm{Cu}-\mathrm{Sn}$ reaction is relied on for electronic interconnections that involve electronic products with a total commercial value second to none. It is no wonder that the $\mathrm{Cu}-$ Sn reaction is probably the most extensively studied one in binary metallic systems. Nevertheless, even for such an important system with such a long history, there are still many un-resolved problems. The brittle fracture induced by the Kirkendall voids is one such problem that recently is receiving significant attention.

\subsection{Kirkendall voids formation in solders $/ \mathrm{Cu}$ reactions}

It is well known that at temperatures greater than $50 \sim 60^{\circ} \mathrm{C}$ the reactions between $\mathrm{Cu}$ and Sn-based solders (pure Sn, eutectic PbSn, and $\mathrm{SnAgCu}$, with the exception of $\mathrm{SnZn}$ solders) will produce two reaction products, $\mathrm{Cu}_{6} \mathrm{Sn}_{5}$ and $\mathrm{Cu}_{3} \mathrm{Sn}$. At temperatures lower than $50 \sim 60^{\circ} \mathrm{C}$, only $\mathrm{Cu}_{6} \mathrm{Sn}_{5}$ is detected at the interface [29]. The Kirkendall voids tend to form with $\mathrm{Cu}_{3} \mathrm{Sn}$, and the formation of $\mathrm{Cu}_{6} \mathrm{Sn}_{5}$ alone does not induce the formation of such voids [29, 45-51]. Zeng et al. [50] reported that a large number of Kirkendall voids formed when electroplated $\mathrm{Cu}$ was reacted with eutectic $\mathrm{PbSn}$ solder at $100-150^{\circ} \mathrm{C}$. As shown in Fig. 2(a), these voids located not only at the $\mathrm{Cu} / \mathrm{Cu}_{3} \mathrm{Sn}$ interface but also within the $\mathrm{Cu}_{3} \mathrm{Sn}$ layer. The formation of the Kirkendall voids is not limited to the eutectic PbSn solder. The Kirkendall voids were also reported to form when electroplated $\mathrm{Cu}$ was reacted with $\mathrm{SnAgCu}$ solder [46], as shown in Fig. 2(b), or pure $\mathrm{Sn}$ [29]. Without question, the rapid diffusion of $\mathrm{Cu}$ out of the $\mathrm{Cu}_{3} \mathrm{Sn}$ layer was the major contributing factor for the formation of these voids. It had been pointed out that both $\mathrm{Cu}$ and $\mathrm{Sn}$ were mobile within $\mathrm{Cu}_{3} \mathrm{Sn}$, although the $\mathrm{Cu}$ flux was somewhat greater than that of the Sn flux (three times greater at $200^{\circ} \mathrm{C}$ ) [52].

The Kirkendall voids accompanying the $\mathrm{Cu}_{3} \mathrm{Sn}$ growth raise serious reliability concerns because excessive void formation increases the potential for brittle interfacial fracture $[45-47,50]$. The voids in Fig. 2(b) had reached such a high population that they almost aggregated into continuous regions. Such a reliability threat is especially serious at high temperature because $\mathrm{Cu}_{3} \mathrm{Sn}$ only grows at temperatures greater than $50 \sim 60^{\circ} \mathrm{C}$. In brief, there is a need for ways to reduce the $\mathrm{Cu}_{3} \mathrm{Sn}$ growth so that excessive Kirkendall void formation can be avoided.

\section{$2.2 \mathrm{Ni}$ addition to solders}

It had been shown that $\mathrm{Ni}$ addition to $\mathrm{Sn} 3.5 \mathrm{Ag}$ (3.5 wt.\% $\mathrm{Ag}$, balance $\mathrm{Sn}$ ) in amounts as minute as 0.1 wt.\% was able to substantially hinder the $\mathrm{Cu}_{3} \mathrm{Sn}$ growth during soldering [53] as well as during the sequential solid-state aging [54-57]. As shown in Fig. 3,
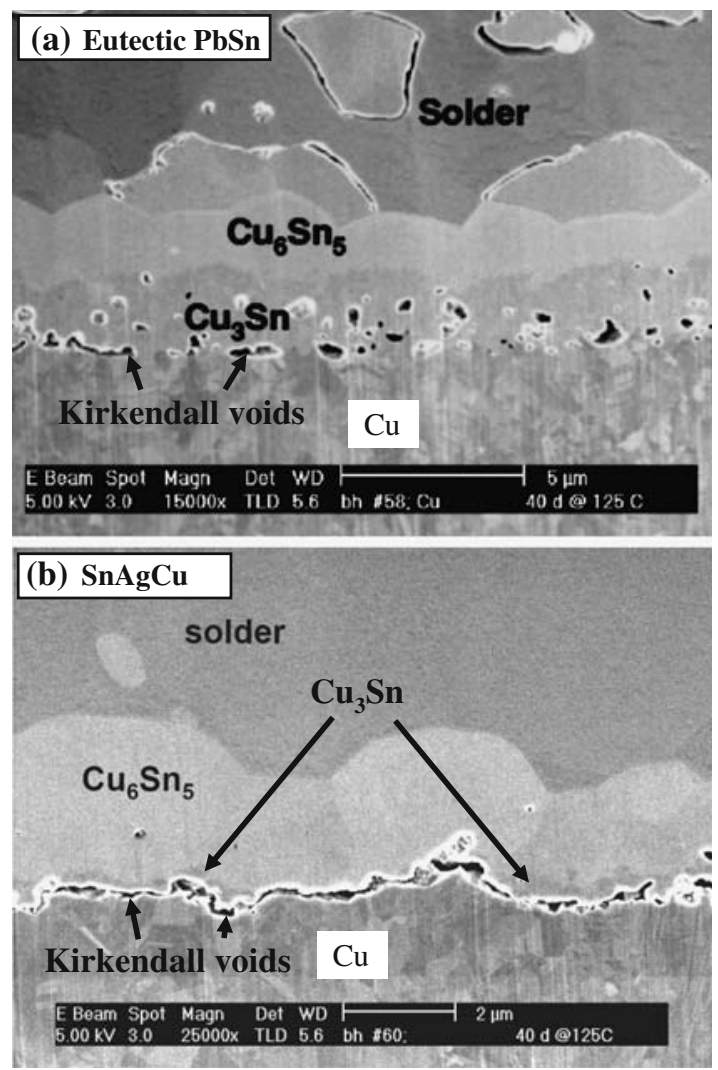

Fig. 2 (a) Secondary electron image showing the Kirkendall voids located within the $\mathrm{Cu}_{3} \mathrm{Sn}$ layer in the reaction between eutectic $\mathrm{PbSn}$ and $\mathrm{Cu}$ at $125^{\circ} \mathrm{C}$ for 40 days [50]. (b) Secondary electron image showing the continuously aggregated Kirkendall voids in the reaction between $\mathrm{SnAgCu}$ and $\mathrm{Cu}$ at $125^{\circ} \mathrm{C}$ for 40 days [46] 


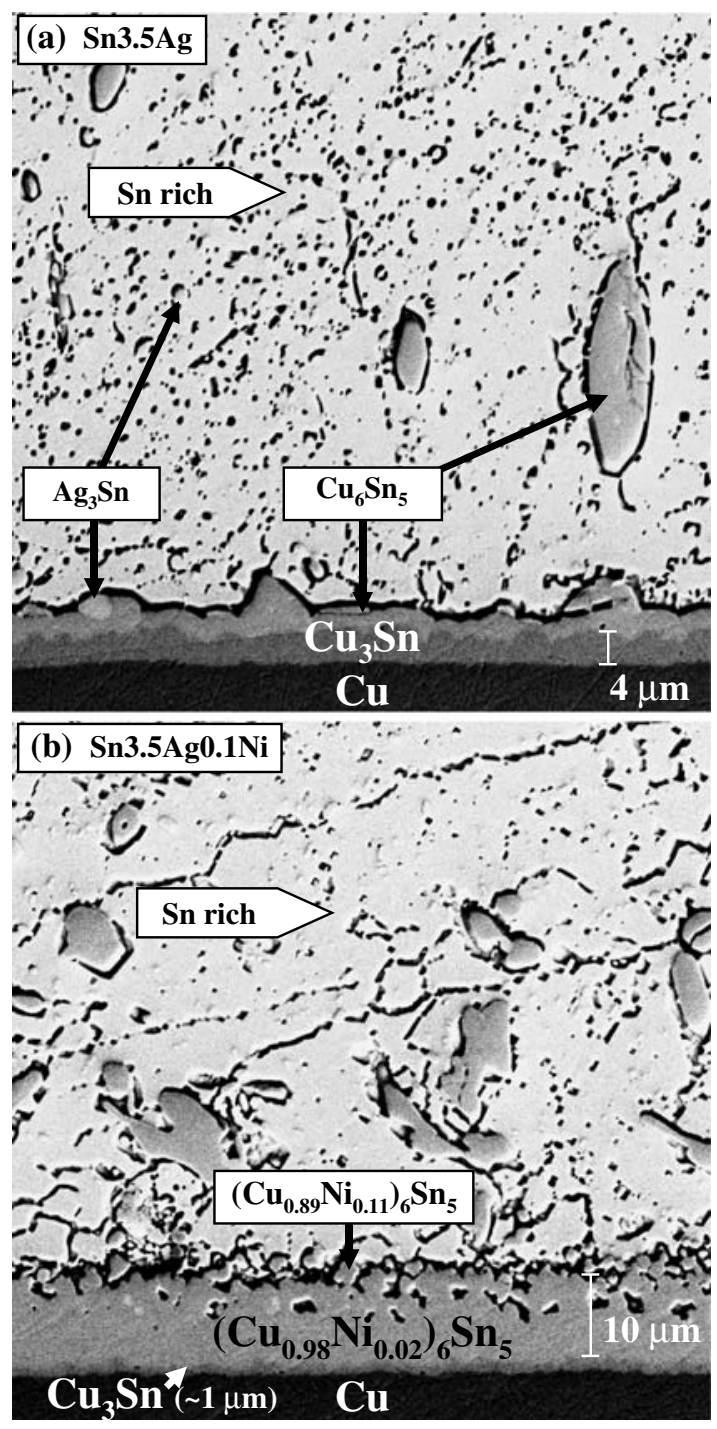

Fig. 3 Backscatter electron micrographs for the $\mathrm{Sn} 3.5 \mathrm{Ag} / \mathrm{Cu}$ interface (a) and the $\mathrm{Sn} 3.5 \mathrm{Ag} 0.1 \mathrm{Ni} / \mathrm{Cu}$ interface (b) that had been aged at $150^{\circ} \mathrm{C}$ for $1,000 \mathrm{~h}$. [54]

the $\mathrm{Cu}_{3} \mathrm{Sn}$ thickness remained very thin even after aging at $150^{\circ} \mathrm{C}$ for $1,000 \mathrm{~h} \mathrm{[54].} \mathrm{As} \mathrm{the} \mathrm{growth} \mathrm{of} \mathrm{Cu}_{3} \mathrm{Sn}$ is the culprit for the formation of the Kirkendall voids, the addition of $\mathrm{Ni}$ can therefore reduce the amount of the Kirkendall voids. In fact, recently it had been shown that the interfacial strength from drop test indeed increase for solders joints with just a small amount of $\mathrm{Ni}$ addition (<1 wt. \%) [56].

Figure 3 also shows that $\mathrm{Ni}$ addition increased the amount of $\mathrm{Cu}_{6} \mathrm{Sn}_{5}$ at the interface compared to that without $\mathrm{Ni}$ addition. In addition, the $\mathrm{Cu}_{6} \mathrm{Sn}_{5}$ phase now possessed a small amount of $\mathrm{Ni}$, and became $\left(\mathrm{Cu}_{1-x}\right.$ $\left.\mathrm{Ni}_{x}\right)_{6} \mathrm{Sn}_{5}$. A close examination of Fig. 3(b) reveals that there were two distinct $\left(\mathrm{Cu}_{1-x} \mathrm{Ni}_{x}\right)_{6} \mathrm{Sn}_{5}$ regions [54]. The inner region was a dense layer of $\left(\mathrm{Cu}_{0.98}\right.$ $\left.\mathrm{Ni}_{0.02}\right)_{6} \mathrm{Sn}_{5}$, and the outer region was actually composed of an aggregate of $\left(\mathrm{Cu}_{0.89} \mathrm{Ni}_{0.11}\right)_{6} \mathrm{Sn}_{5}$ particles. The compositions noted were carefully determined by using the electron probe microanalysis (EPMA). The space between these $\left(\mathrm{Cu}_{0.89} \mathrm{Ni}_{0.11}\right)_{6} \mathrm{Sn}_{5}$ particles was occupied by the solder. It was proposed that the inner region formed during the solid-state aging period, and the outer region was the remains of the $\left(\mathrm{Cu}_{1-x} \mathrm{Ni}_{x}\right)_{6} \mathrm{Sn}_{5}$ formed during the reflow period. This proposition was supported by the micrographs for the as-reflow samples shown in Fig. 4 [54]. It can be seen that $\mathrm{Ni}$ addition induced a thicker layer of $\left(\mathrm{Cu}_{1-x} \mathrm{Ni}_{x}\right)_{6} \mathrm{Sn}_{5}$ during the reflow stage. During the solid-state aging, the region of the aggregate near the $\mathrm{Cu}$ side was converted into the dense $\left(\mathrm{Cu}_{1-x} \mathrm{Ni}_{x}\right)_{6} \mathrm{Sn}_{5}$ layer, and what was left of the aggregate showed up in Fig. 3(b). The outer $\left(\mathrm{Cu}_{1-x} \mathrm{Ni}_{x}\right)_{6} \mathrm{Sn}_{5}$ region in Fig. 4(b) apparently served as a short cut for Sn diffusion, that enhanced the $\mathrm{Cu}_{6} \mathrm{Sn}_{5}$ growth but inhibited the growth of $\mathrm{Cu}_{3} \mathrm{Sn}$. Consequently, the un-desirable growth of $\mathrm{Cu}_{3} \mathrm{Sn}$ was hindered. Another possibility for the shrinkage of $\mathrm{Cu}_{3} \mathrm{Sn}$ could be attributed to the substitution of $\mathrm{Ni}$ into the $\mathrm{Cu}$ sublattice of $\mathrm{Cu}-\mathrm{Sn}$ compound(s), to reduce the interdiffusion coefficient [56].

The observation that $\mathrm{Ni}$ addition could induce a larger amount of $\left(\mathrm{Cu}_{1-x} \mathrm{Ni}_{x}\right)_{6} \mathrm{Sn}_{5}$ during reflow deserves more attention. It is proposed that this phenomenon is closely related to the $\mathrm{Cu}$ metastable solubility and the $\mathrm{Cu}$ equilibrium solubility in the solder. Here, these two types of solubility will be briefly discussed first. During the reaction of $\mathrm{Cu}$ with molten solders, it is often observed that in some regions bare $\mathrm{Cu}$ was in direct contact with the molten solders without being covered
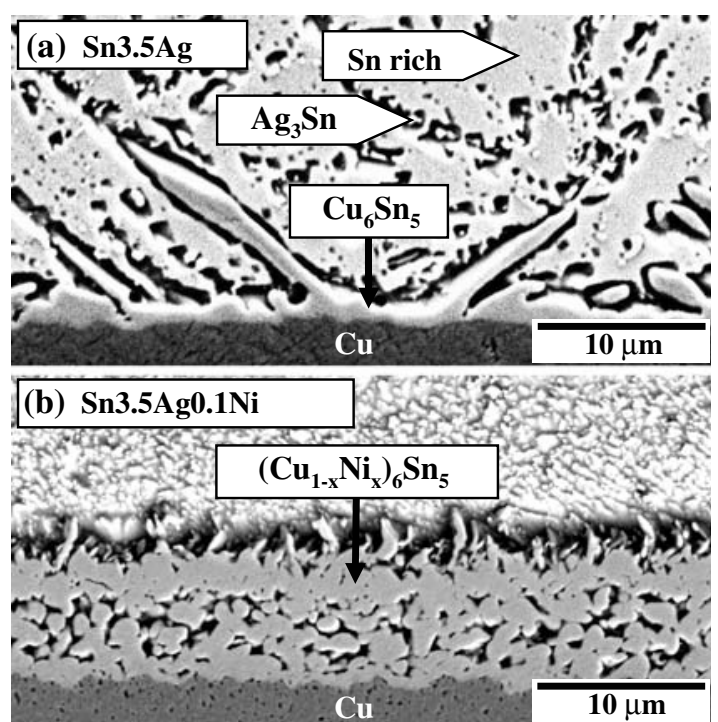

Fig. 4 Backscatter electron micrographs for the $\mathrm{Sn} 3.5 \mathrm{Ag} / \mathrm{Cu}$ interface (a) and the $\mathrm{Sn} 3.5 \mathrm{Ag} 0.1 \mathrm{Ni} / \mathrm{Cu}$ interface $(\mathbf{b})$ after reflow soldering at $240^{\circ} \mathrm{C}$ for $2 \mathrm{~min}$. [54] 
by $\mathrm{Cu}_{6} \mathrm{Sn}_{5}$ or $\mathrm{Cu}_{3} \mathrm{Sn}$. Under such circumstance, $\mathrm{Cu}$ is in a local, metastable equilibrium with solders, and a metastable solubility of $\mathrm{Cu}$ in solders will eventually be established. According to thermodynamic arguments, this metastable solubility is always higher than the stable solubility of $\mathrm{Cu}$ in solders at the same temperature. As had been pointed out by Laurial et al. [29], it is the metastable solubility that determines the dissolution rate of $\mathrm{Cu}$ into molten solders because during dissolution bare $\mathrm{Cu}$ is in direct contact with the solder. The metastable solubility cannot be determined experimentally, and has to be calculated by approaches such as the CALPHAD method [29]. As for the equilibrium solubility, some experimental results are available. Shown in Fig. 5 is the Sn-rich corner of the $\mathrm{Cu}-\mathrm{Ni}-\mathrm{Sn}$ isotherm at $240^{\circ} \mathrm{C}$. This isotherm is drawn based on the previously published isotherms [19, 29, $41]$ and the solubility data from the $\mathrm{Cu}-\mathrm{Sn}[58,65]$ and $\mathrm{Ni}-\mathrm{Sn}$ [59] binary systems. This isotherm shows that the addition of $\mathrm{Ni}$ into molten $\mathrm{Sn}$ can substantially decrease the $\mathrm{Cu}$ solubility in $\mathrm{Sn}$. While the equilibrium solubility of $\mathrm{Cu}$ in $\mathrm{Sn}$ is sensitive to the presence of $\mathrm{Ni}$, the metastable solubility of $\mathrm{Cu}$ in $\mathrm{Sn}$ must be less sensitive to minor $\mathrm{Ni}$ additions from the arguments of the common tangent construction of the Gibbs free energies of the phases involved. Under the assumption that the $\mathrm{Cu}$ metastable solubility in $\mathrm{Sn}$ is indeed insensitive to the presence of $\mathrm{Ni}$, one can conclude that the $\mathrm{Cu}$ dissolution rate into $\mathrm{Sn}$ is insensitive to the presence of $\mathrm{Ni}$. In other words, adding $\mathrm{Ni}$ to $\mathrm{Sn}$ will not decrease the $\mathrm{Cu}$ dissolution flux into molten solders. Because the $\mathrm{Cu}$ flux entering $\mathrm{Sn}$ does not decrease with $\mathrm{Ni}$ addition and because the equilibrium $\mathrm{Cu}$ solubility

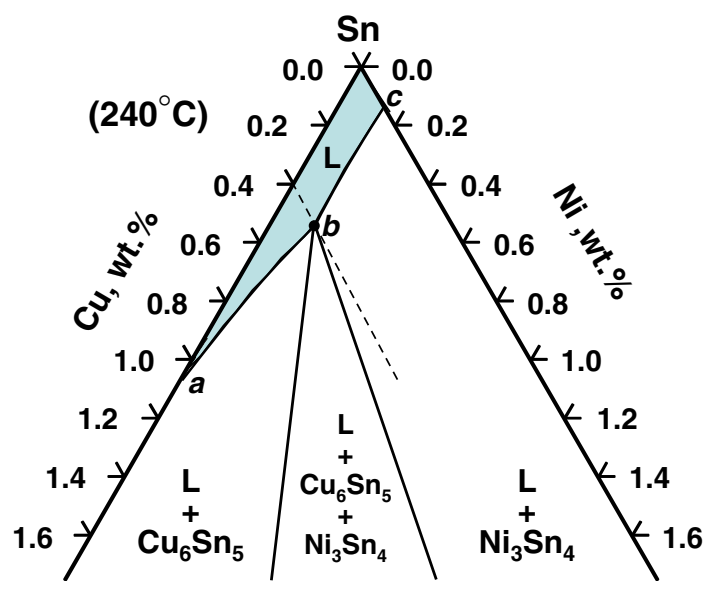

Fig. 5 Schematic drawing showing the $\mathrm{Sn}$-corner of the $\mathrm{Cu}-\mathrm{Ni}-$ $\mathrm{Sn}$ isotherm at $240^{\circ} \mathrm{C}$. This isotherm is drawn based on the previously published isotherms $[19,29,41]$ and the solubility data from the $\mathrm{Cu}-\mathrm{Sn}[58,65]$ and $\mathrm{Ni}-\mathrm{Sn}[59]$ binary systems does decrease substantially with the $\mathrm{Ni}$ addition, the amount of $\left(\mathrm{Cu}_{1-x} \mathrm{Ni}_{x}\right)_{6} \mathrm{Sn}_{5}$ at the interface has to increase as had been observed in Fig. 4.

The way Ni was introduced into the reacting system did not seem to matter as far as hindering the $\mathrm{Cu}_{3} \mathrm{Sn}$ growth was concerned. It had been reported that the growth of $\mathrm{Cu}_{3} \mathrm{Sn}$ was hindered even if Ni-alloyed $\mathrm{Cu}$ substrates were used. These substrates included $\mathrm{Cu}$ alloyed with 6-9 wt.\% $\mathrm{Ni}$ [60] and $\mathrm{Cu}$ alloyed with 15 at.\% Ni [29]. This fact seems to support the view that dissolution plays a very important role during liquid/solid reaction because $\mathrm{Ni}$ in $\mathrm{Cu}-\mathrm{Ni}$ alloys must dissolve into $\mathrm{Sn}$ first to function as an additive of the solders.

\section{Effects of $\mathrm{Cu}$ on the reactions between Sn-based solders and $\mathrm{Ni}$}

According to the binary phase diagram [59], there are three stable intermetallic compounds, $\mathrm{Ni}_{3} \mathrm{Sn}, \mathrm{Ni}_{3} \mathrm{Sn}_{2}$, and $\mathrm{Ni}_{3} \mathrm{Sn}_{4}$, in the Ni-Sn system. However, when $\mathrm{Ni}$ reacted with $\mathrm{Sn}$ at temperatures relevant to soldering, only $\mathrm{Ni}_{3} \mathrm{Sn}_{4}$ was observed $[29,61,62]$. The other two compounds were observed only at higher temperatures, outside the usual operating range of soldering $[29,61,62]$. The reaction rate of $\mathrm{Ni}$ with solder is roughly one order of magnitude lower than that of $\mathrm{Cu}$, and this is one of the reasons for Ni being a popular diffusion barrier material [3].

By using the microstructure features of the grains, it had been proposed that $\mathrm{Ni}$ was the dominant diffusing species in $\mathrm{Ni}_{3} \mathrm{Sn}$ and $\mathrm{Ni}_{3} \mathrm{Sn}_{2}$, and $\mathrm{Sn}$ was the dominant diffusing species in $\mathrm{Ni}_{3} \mathrm{Sn}_{4}$ [63]. A marker experiment had been performed to verify if $\mathrm{Sn}$ was indeed the dominant diffusing species in $\mathrm{Ni}_{3} \mathrm{Sn}_{4}$ [64]. In that study, a layer of $2 \mu \mathrm{m}$ Ti film was deposited on a Ni substrate. The Ti layer was then patterned into $10 \mu \mathrm{m}$ wide thin strips to serve as the markers. As shown in Fig. 6(a), the spacing between neighboring Ti strips was $40 \mu \mathrm{m}$. The sample was then dipped into pure molten $\mathrm{Sn}$ at $250^{\circ} \mathrm{C}$ for $10 \mathrm{~min}$ to produce the diffusion couple shown in Fig. 6(b). The resulting diffusion couple after aging at $225^{\circ} \mathrm{C}$ for $1,000 \mathrm{~h}$ is shown in Fig. 6(c). From the location of the $\mathrm{Ti}$ markers after aging, one can conclude that $\mathrm{Sn}$ is indeed the dominant diffusing species in $\mathrm{Ni}_{3} \mathrm{Sn}_{4}$.

Although the reaction between $\mathrm{Ni}$ and pure Sn only produces $\mathrm{Ni}_{3} \mathrm{Sn}_{4}$ at temperatures relevant to soldering, the reaction between $\mathrm{Ni}$ and $\mathrm{Sn}$ alloys with a small amount of $\mathrm{Cu}$ is very complicated (see Sect. 3.1). Unfortunately, the common lead-free solders recommended by various national or international organizations all 

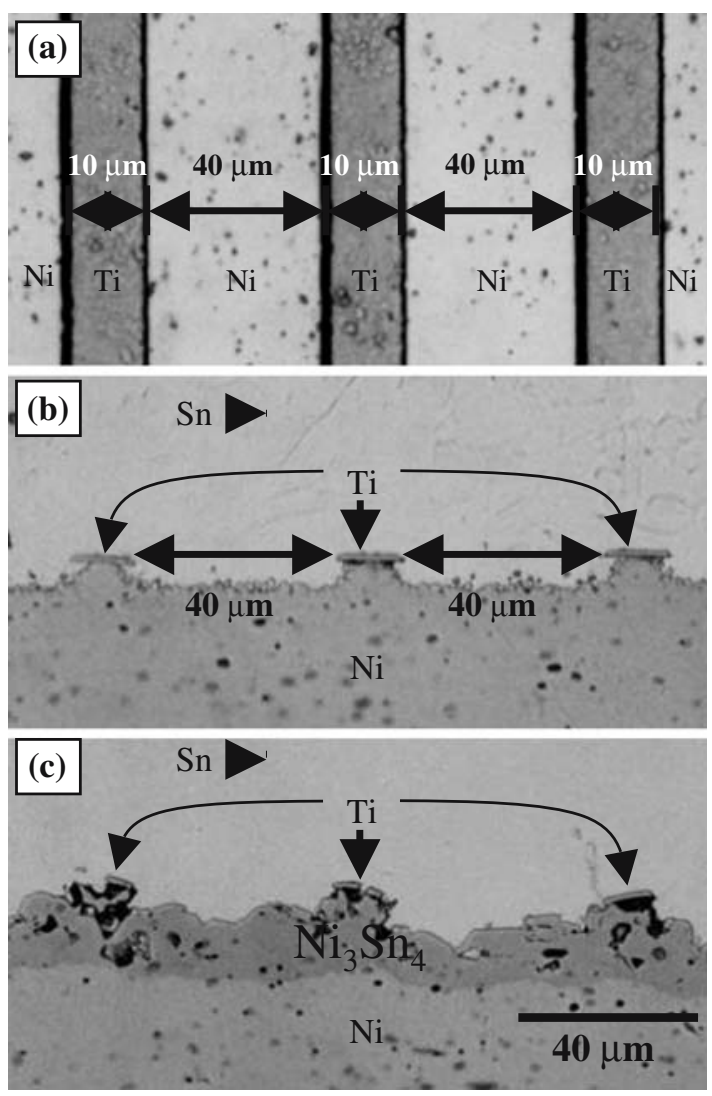

Fig. 6 (a) Optical micrograph showing the plane-view of a $\mathrm{Ni}$ substrate that had been deposited with Ti stripes as markers. (b) Cross-sectional view of the $\mathrm{Ni} / \mathrm{Sn}$ diffusion couple before aging. (c) After aging at $225^{\circ} \mathrm{C}$ for $1,000 \mathrm{~h}$. [64]

have $\mathrm{Cu}$ as a minor constituent (Table 1), and the allowance for the concentration variation for each element is typically $\pm 0.2 \mathrm{wt}$. $\%$, a customary adoption of the practice from the eutectic PbSn solder. As will be shown below, this $\pm 0.2 \mathrm{wt}$. \% difference can change the compound formed at the interface after reflow.

\subsection{Uncomplicated $\mathrm{Cu}$ concentration effect}

During the reflow of $\mathrm{SnCu}$ or $\mathrm{SnAgCu}$ solders over those soldering pads that have the $\mathrm{Ni}, \mathrm{Ni}(\mathrm{P})$, and $\mathrm{Ni}(\mathrm{V})$ underlayer, the reaction product(s) at the interface are very sensitive to the $\mathrm{Cu}$ concentration in the solders. After the first report [73] of this $\mathrm{Cu}$ sensitivity a few years ago, over forty papers had been published on this subject. As summarized in Table 2, the results of these studies as a whole are quite consistent, even though different reflow conditions and different $\mathrm{Ni}$ substrates, including $\mathrm{Ni}, \mathrm{Ni}(\mathrm{P}), \mathrm{Ni}(\mathrm{V})$, or $\mathrm{Au} / \mathrm{Ni}$, had been used. As shown in Table 2, when the $\mathrm{Cu}$ concentration was low $\left(<0.3\right.$ wt.\%), only $\left(\mathrm{Ni}_{1-y} \mathrm{Cu}_{y}\right)_{3} \mathrm{Sn}_{4}$ formed at the interface. When the $\mathrm{Cu}$ concentration increased to $0.4-0.5$ wt. \%, both $\left(\mathrm{Ni}_{1-y} \mathrm{Cu}_{y}\right)_{3} \mathrm{Sn}_{4}$ and $\left(\mathrm{Cu}_{1-x} \mathrm{Ni}_{x}\right)_{6} \mathrm{Sn}_{5}$ formed. When the $\mathrm{Cu}$ concentration increased above 0.5 wt. \%, only $\left(\mathrm{Cu}_{1-x} \mathrm{Ni}_{x}\right)_{6} \mathrm{Sn}_{5}$ formed. In a few specific cases [28, 86, 89-91, 96, 104, 105], where the reported results seemed to differ from the trend shown in Table 2 at the first sight, the inconsistency in fact could be attributed to the so-called "solder volume effect," which is to be discussed in the next section.

To exclude other factors that may obscure the discussion, the reaction between a large amount of solder and a piece of thick, high purity $\mathrm{Ni}$ substrate will be examined first. Since the amount of solder was large, one can then assume that the solder composition remained constant during the reaction even though $\mathrm{Cu}$ was being extracting out of the solder to be incorporated into the reaction product(s). In addition, since the Ni substrate was thick, the Ni substrate was never totally consumed. In some aspects, the system approached the limit of classical infinite/infinite diffusion couple. As shown in Fig. 7(a), the reaction product at the interface was a continuous layer of $\left(\mathrm{Ni}_{1-y}\right.$ $\left.\mathrm{Cu}_{y}\right)_{3} \mathrm{Sn}_{4}$ when the $\mathrm{Cu}$ concentration was $0.2 \mathrm{wt} \%$. When the $\mathrm{Cu}$ concentration increased to $0.4 \mathrm{wt} . \%$, discontinuous $\left(\mathrm{Cu}_{1-x} \mathrm{Ni}_{x}\right)_{6} \mathrm{Sn}_{5}$ particles began to form over the $\left(\mathrm{Ni}_{1-y} \mathrm{Cu}_{y}\right)_{3} \mathrm{Sn}_{4}$ continuous layer, Fig. 7(b). When the $\mathrm{Cu}$ concentration increased to $0.5 \mathrm{wt} . \%$, both $\left(\mathrm{Cu}_{1-x} \mathrm{Ni}_{x}\right)_{6} \mathrm{Sn}_{5}$ and $\left(\mathrm{Ni}_{1-y} \mathrm{Cu}_{y}\right)_{3} \mathrm{Sn}_{4}$ were continuous, Fig. 7(c). When the $\mathrm{Cu}$ concentration reached 0.6 wt. \%, only a continuous $\left(\mathrm{Cu}_{1-x} \mathrm{Ni}_{x}\right)_{6} \mathrm{Sn}_{5}$ layer was present, Fig. 7(d). The crystal structures of the products had been verified by the X-ray diffraction (XRD) patterns shown in Fig. 8 [73, 106]. To obtain such
Table 1 Lead-free solders recommended by various national or international organizations

\footnotetext{
a $\mathrm{SnAgCu}$ with additive(s)

${ }^{\mathrm{b}}$ Under consideration
}

\begin{tabular}{ll}
\hline SnAgCu composition (wt. \%) & Recommending organizations \\
\hline $\mathrm{Sn}-(3.5 \pm 0.3) \mathrm{Ag}-(0.9 \pm 0.2) \mathrm{Cu}$ & NIST (ternary eutectic) [65] \\
$\mathrm{Sn}-(3.9 \pm 0.2) \mathrm{Ag}-(0.6 \pm 0.2) \mathrm{Cu}$ & NEMI (N. America) [66] \\
$\mathrm{Sn}-(3.4 \sim 4.1) \mathrm{Ag}-(0.45 \sim 0.9) \mathrm{Cu}$ & Soldertec-ITRI (UK) [67] \\
$\mathrm{Sn}-3.8 \mathrm{Ag}-0.7 \mathrm{Cu}$ & IDEALS (EU) [68] \\
$\mathrm{Sn}-3.0 \mathrm{Ag}-0.5 \mathrm{Cu}$ & JEITA (Japan) [69] \\
$\mathrm{Sn}-4.0 \mathrm{Ag}-0.5 \mathrm{Cu}$ & - \\
${ }^{\mathrm{a}} \mathrm{Sn}-2.5 \mathrm{Ag}-0.8 \mathrm{Cu}-0.5 \mathrm{Sb}$ & AIM, CASTIN alloy [70] \\
${ }^{\mathrm{a}} \mathrm{Sn}-3.5 \mathrm{Ag}-0.5 \mathrm{Cu}-1.0 \mathrm{Zn}$ & NCMS [71] \\
${ }^{\mathrm{b}} \mathrm{Sn}-3.0 \mathrm{Ag}-0.6 \mathrm{Cu}-0.019 \mathrm{Ce}$ & China RoHS Standard Committee [72] \\
\end{tabular}


Table 2 Summary of the reported reaction products between $\mathrm{SnAgCu}$ solders and various Ni-bearing soldering pads after reflow

\begin{tabular}{|c|c|c|c|c|c|}
\hline $\mathrm{Cu}($ wt. \%) & Ag (wt.\%) & Sn (wt.\%) & Base metal & Intermetallic(s) & References \\
\hline 0.0 & $3.5-3.9$ & Balance & $\begin{array}{l}\mathrm{Ni} \text { and } \mathrm{Ni}(\mathrm{P}) \\
\mathrm{Au} / \mathrm{Ni} \text { and } \mathrm{Au} / \mathrm{Ni}(\mathrm{P})\end{array}$ & $\begin{array}{l}\mathrm{Ni}_{3} \mathrm{Sn}_{4} \\
\mathrm{Ni}_{3} \mathrm{Sn}_{4}\end{array}$ & $\begin{array}{l}{[26,74-77]} \\
{[20,22,23,25,28,31,78-85]}\end{array}$ \\
\hline 0.1 & 0 & Balance & $\mathrm{Ni}$ & $\mathrm{Ni}_{3} \mathrm{Sn}_{4}$ & [86] \\
\hline 0.2 & $0-3.9$ & Balance & $\mathrm{Ni}$ and $\mathrm{Ni}(\mathrm{P})$ & $(\mathrm{Ni}, \mathrm{Cu})_{3} \mathrm{Sn}_{4}$ & {$[32,73,75,87,88]$} \\
\hline 0.3 & $0-3.0$ & Balance & $\mathrm{Ni}$ & $(\mathrm{Ni}, \mathrm{Cu})_{3} \mathrm{Sn}_{4}$ & {$[86,89]$} \\
\hline 0.4 & $0-3.9$ & Balance & $\begin{array}{l}\mathrm{Ni} \\
\mathrm{Au} / \mathrm{Ni}(\mathrm{P})\end{array}$ & $\begin{array}{l}(\mathrm{Ni}, \mathrm{Cu})_{3} \mathrm{Sn}_{4} /(\mathrm{Cu}, \mathrm{Ni})_{6} \mathrm{Sn}_{5} \\
(\mathrm{Ni}, \mathrm{Cu})_{3} \mathrm{Sn}_{4} /(\mathrm{Cu}, \mathrm{Ni})_{6} \mathrm{Sn}_{5}\end{array}$ & $\begin{array}{l}{[75,87-91]} \\
{[33]}\end{array}$ \\
\hline 0.5 & $1.0-4.0$ & Balance & $\begin{array}{l}\mathrm{Ni} \text { and } \mathrm{Ni}(\mathrm{P}) \\
\mathrm{Au} / \mathrm{Ni} \text { and } \mathrm{Au} / \mathrm{Ni}(\mathrm{P}) \\
\mathrm{Ni} \text { and } \mathrm{Ni}(\mathrm{P}) \\
\mathrm{Au} / \mathrm{Ni} \text { and } \mathrm{Au} / \mathrm{Ni}(\mathrm{P})\end{array}$ & $\begin{array}{l}(\mathrm{Cu}, \mathrm{Ni})_{6} \mathrm{Sn}_{5} \\
(\mathrm{Cu}, \mathrm{Ni})_{6} \mathrm{Sn}_{5} \\
(\mathrm{Ni}, \mathrm{Cu})_{3} \mathrm{Sn}_{4} /(\mathrm{Cu}, \mathrm{Ni})_{6} \mathrm{Sn}_{5} \\
(\mathrm{Ni}, \mathrm{Cu})_{3} \mathrm{Sn}_{4} /(\mathrm{Cu}, \mathrm{Ni})_{6} \mathrm{Sn}_{5}\end{array}$ & $\begin{array}{l}{[89-91]} \\
{[21,25,34,82,83,85,92]} \\
{[32,75,88]} \\
{[21,28,81,93]}\end{array}$ \\
\hline 0.6 & $0-3.9$ & Balance & $\mathrm{Ni}$ & $(\mathrm{Cu}, \mathrm{Ni})_{6} \mathrm{Sn}_{5}$ & {$[73,75,88-91]$} \\
\hline 0.7 & $0-3.8$ & Balance & $\begin{array}{l}\mathrm{Ni} \text { and } \mathrm{Ni}(\mathrm{P}) \\
\mathrm{Au} / \mathrm{Ni} \text { and } \mathrm{Au} / \mathrm{Ni}(\mathrm{P})\end{array}$ & $\begin{array}{l}(\mathrm{Cu}, \mathrm{Ni})_{6} \mathrm{Sn}_{5} \\
(\mathrm{Cu}, \mathrm{Ni})_{6} \mathrm{Sn}_{5}\end{array}$ & $\begin{array}{l}{[27,32,75,86,87,94,95]} \\
{[19,28,30,96-101]}\end{array}$ \\
\hline 0.75 & 3.5 & Balance & $\begin{array}{l}\mathrm{Au} / \mathrm{Ni} \text { and } \mathrm{Au} / \mathrm{Ni}(\mathrm{P}) \\
\mathrm{Ni} \text { and } \mathrm{Ni}(\mathrm{P})\end{array}$ & $\begin{array}{l}(\mathrm{Cu}, \mathrm{Ni})_{6} \mathrm{Sn}_{5} \\
(\mathrm{Cu}, \mathrm{Ni})_{6} \mathrm{Sn}_{5}\end{array}$ & $\begin{array}{l}{[102]} \\
{[22,23,81,102]}\end{array}$ \\
\hline 0.8 & $0-3.9$ & Balance & $\begin{array}{l}\mathrm{Au} / \mathrm{Ni} \text { and } \mathrm{Au} / \mathrm{Ni}(\mathrm{P}) \\
\mathrm{Ni}\end{array}$ & $\begin{array}{l}(\mathrm{Cu}, \mathrm{Ni})_{6} \mathrm{Sn}_{5} \\
(\mathrm{Cu}, \mathrm{Ni})_{6} \mathrm{Sn}_{5}\end{array}$ & $\begin{array}{l}{[75,88]} \\
{[25]}\end{array}$ \\
\hline 0.9 & 0 & Balance & $\mathrm{Ni}$ & $(\mathrm{Cu}, \mathrm{Ni})_{6} \mathrm{Sn}_{5}$ & {$[86]$} \\
\hline 1.0 & $3.5-3.9$ & Balance & $\begin{array}{l}\mathrm{Ni} \text { and } \mathrm{Ni}(\mathrm{P}) \\
\mathrm{Au} / \mathrm{Ni}\end{array}$ & $\begin{array}{l}(\mathrm{Cu}, \mathrm{Ni})_{6} \mathrm{Sn}_{5} \\
(\mathrm{Cu}, \mathrm{Ni})_{6} \mathrm{Sn}_{5}\end{array}$ & $\begin{array}{l}{[32,75,87]} \\
{[103]}\end{array}$ \\
\hline 1.5 & 0 & Balance & $\mathrm{Ni}$ & $(\mathrm{Cu}, \mathrm{Ni})_{6} \mathrm{Sn}_{5}$ & [86] \\
\hline 1.7 & 4.7 & Balance & $\mathrm{Ni}$ & $(\mathrm{Cu}, \mathrm{Ni})_{6} \mathrm{Sn}_{5}$ & [103] \\
\hline 3.0 & $0-3.9$ & Balance & $\begin{array}{l}\mathrm{Ni} \\
\mathrm{Au} / \mathrm{Ni}\end{array}$ & $\begin{array}{l}(\mathrm{Cu}, \mathrm{Ni})_{6} \mathrm{Sn}_{5} \\
(\mathrm{Cu}, \mathrm{Ni})_{6} \mathrm{Sn}_{5}\end{array}$ & $\begin{array}{l}{[75,94]} \\
{[100]}\end{array}$ \\
\hline
\end{tabular}

Only those studies that used reflow conditions similar to the industry practices are included in this table

patterns, the solders had to be etched away first by using a proper etching solution, and the remaining reaction products as well as the $\mathrm{Ni}$ substrate were then subjected to the measurements. The amount of the discontinuous $\left(\mathrm{Cu}_{1-x} \mathrm{Ni}_{x}\right)_{6} \mathrm{Sn}_{5}$ particles in Fig. 7(b) was too small to allow for a positive identification through XRD, but the identity of these particles was established by using the transmission electron microscopy (TEM) shown in Fig. 9 [106]. The discontinuous $\left(\mathrm{Cu}_{1-x}\right.$ $\left.\mathrm{Ni}_{x}\right)_{6} \mathrm{Sn}_{5}$ particles in Fig. 7 (b) and the continuous $\left(\mathrm{Cu}_{1-x}\right.$ $\left.\mathrm{Ni}_{x}\right)_{6} \mathrm{Sn}_{5}$ layer in Fig. 7(d) might have different formation mechanisms. Those $\left(\mathrm{Cu}_{1-x} \mathrm{Ni}_{x}\right)_{6} \mathrm{Sn}_{5}$ grains in Fig. 7(d) formed through the direct reaction of $\mathrm{Ni}$ and the solder, and accordingly these grains had a preferred growth direction of 0001 as shown in Fig. 10 [106]. This preferred growth direction had also been observed during the reaction between $\mathrm{Ni}$ and the eutectic $\mathrm{PbSn}$ solder with $0.5 \mathrm{wt} . \% \mathrm{Cu}$ dopant [107]. On the other hand, those discontinuous $\left(\mathrm{Cu}_{1-x} \mathrm{Ni}_{x}\right)_{6} \mathrm{Sn}_{5}$ particles in Fig. 7(b) did not show any preferred orientation.

To understand this strong $\mathrm{Cu}$ concentration dependency, one needs to have the relevant phase diagram information for the $\mathrm{Sn}-\mathrm{Ag}-\mathrm{Cu}-\mathrm{Ni}$ system. Although $\mathrm{Ag}$ is an important constituent controlling the solidification microstructure of the solder itself [44, 93, 108-112], it has been shown that $\mathrm{Ag}$ is inert as far as the interfacial reaction is concerned [73, 75, 87]. Accordingly, the Sn$\mathrm{Cu}-\mathrm{Ni}$ ternary phase diagram is sufficient for the present purpose. The $\mathrm{Sn}-\mathrm{Cu}-\mathrm{Ni}$ isotherm had been measured by two independent groups $[113,114]$, and the results are reasonably consistent. The $240^{\circ} \mathrm{C} \mathrm{Sn}-\mathrm{Cu}-\mathrm{Ni}$ isotherm basing on these two studies is shown in Fig. 11. The Sn-rich corner of this isotherm is shown in Fig. 5. There is some evidence for the existence of a ternary compound (Ni26Cu29Sn45, atomic percent) [115]. If this compound is indeed stable, then the isotherm in Fig. 11 is only a metastable isotherm [29, 41]. Nevertheless, as far as soldering is concerned, the isotherm shown in Fig. 11 is still adequate, as results from most soldering reaction experiments were observed to follow the phase relationships shown in Fig. 11.

As shown in Fig. 5, the molten Sn phase (L) has a phase boundary $\mathrm{a}-\mathrm{b}-\mathrm{c}$, which is composed of two segments $\mathrm{a}-\mathrm{b}$ and $\mathrm{b}-\mathrm{c}$. Along $\mathrm{a}-\mathrm{b}, \mathrm{L}$ is in equilibrium with the $\mathrm{Cu}_{6} \mathrm{Sn}_{5}$ phase, and $\mathrm{L}$ is in equilibrium with $\mathrm{Ni}_{3} \mathrm{Sn}_{4}$ along $\mathrm{b}-\mathrm{c}$. The point $\mathrm{b}$ represents that $\mathrm{L}$ is in equilibrium with both $\mathrm{Cu}_{6} \mathrm{Sn}_{5}$ and $\mathrm{Ni}_{3} \mathrm{Sn}_{4}$. As indicated by the dash line passing through $\mathrm{b}, \mathrm{b}$ has a $\mathrm{Cu}$ concentration of about 0.4 wt. $\%$. In other words, when the $\mathrm{Cu}$ concentration in the solder is $0.4 \mathrm{wt} . \%$, this solder is in equilibrium with both $\mathrm{Cu}_{6} \mathrm{Sn}_{5}$ and $\mathrm{Ni}_{3} \mathrm{Sn}_{4}$. This explains why both these two phases form as shown in Fig. 7(b). When the $\mathrm{Cu}$ concentration is less than $0.4 \mathrm{wt} . \%$, the solder in this range is in equilibrium with only $\mathrm{Ni}_{3} \mathrm{Sn}_{4}$, and consequently only this phase forms as shown in Fig. 7(a). When the $\mathrm{Cu}$ concentration is 
Fig. 7 Micrographs showing the $\mathrm{Sn} 3.9 \mathrm{AgxCu} / \mathrm{Ni}$ interfaces after $250^{\circ} \mathrm{C}$ soldering for $10 \mathrm{~min}$. The left column is cross-sectional view, and the right column is top view. The reaction couples here approached the classical infinite/infinite diffusion couples. [73, 75]
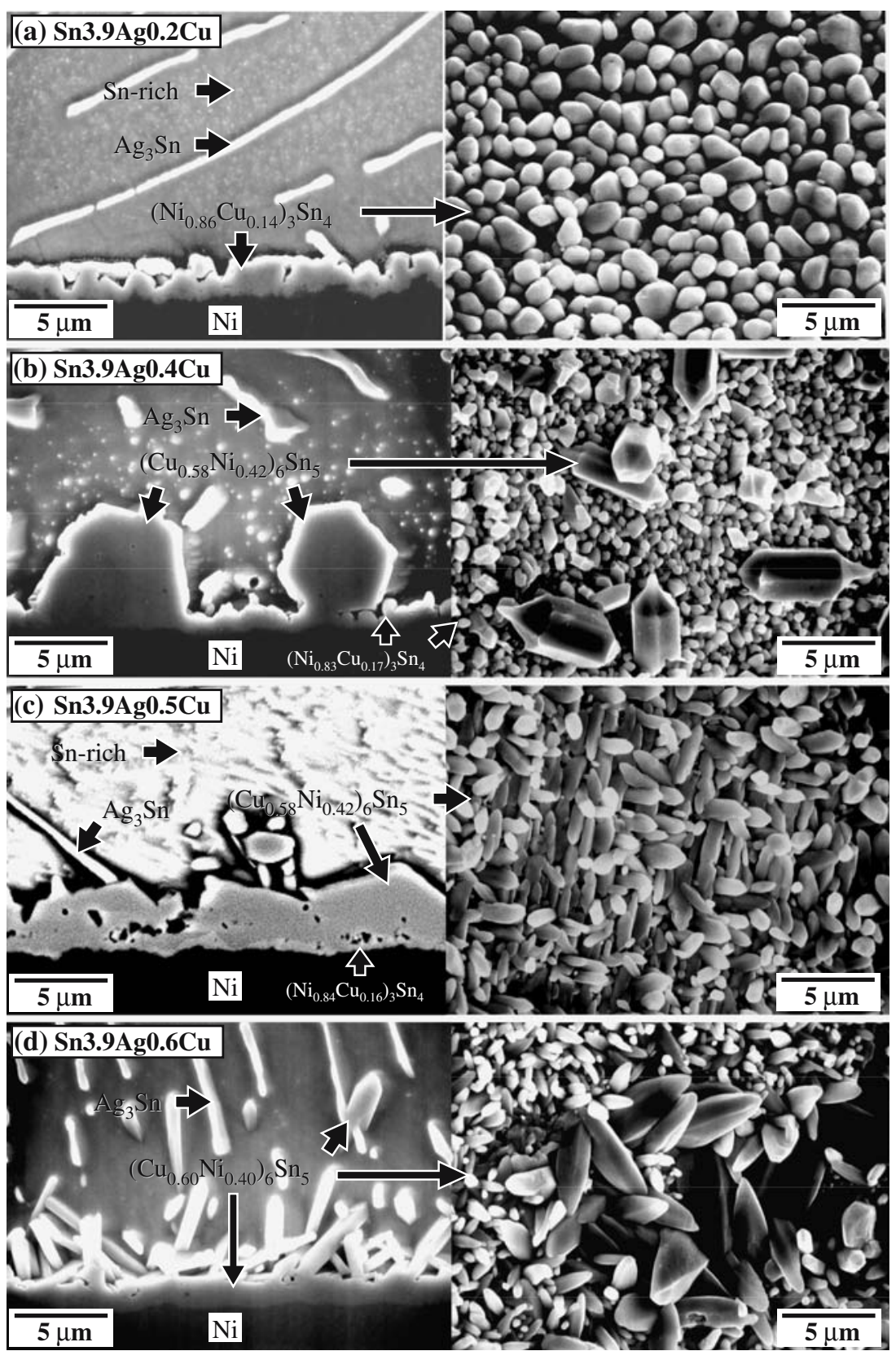

higher than $0.4 \mathrm{wt} \%$, $\mathrm{L}$ is in equilibrium with only $\mathrm{Cu}_{6} \mathrm{Sn}_{5}$, and only this phase can be immediately next to L, as shown in Fig. 7(c) and (d).

\subsection{Solder volume effect during reaction with molten solders (reflow)}

During reflow and the subsequent aging, $\mathrm{Cu}$ atoms are incorporated into the intermetallic(s) [i.e., $\left(\mathrm{Cu}_{1-x}\right.$ $\left.\mathrm{Ni}_{x}\right)_{6} \mathrm{Sn}_{5}$ and $\left.\left(\mathrm{Ni}_{1-y} \mathrm{Cu}_{y}\right)_{3} \mathrm{Sn}_{4}\right]$ at the interface. As the intermetallic(s) grow, more $\mathrm{Cu}$ atoms are being consumed. The results presented in the previous section were for the condition that the amount of the solder was relatively large so that the supply of $\mathrm{Cu}$ was also large. The average $\mathrm{Cu}$ concentration in the solder could consequently remain nearly constant. The thermodynamic condition at the interface was thus static, and the formation of one compound or another was more or less dictated by the thermodynamics. For a real solder joint in array-array packages, the supply of $\mathrm{Cu}$ is actually very limited because the solder volume is quite small in the first place, and secondly the $\mathrm{Cu}$ concentration in $\mathrm{SnAgCu}$ solder is always less than a few atomic percents (see Table 2). The $\mathrm{Cu}$ concentration can decrease noticeably as the intermetallic(s) grow [89-91]. As the $\mathrm{Cu}$ concentration changes, the type of the equilibrium intermetallic at the interface might also change. Now the condition at the 
Fig. 8 XRD patterns for the reaction products in originated from the Ni layer beneath the intermetallic compounds [73, 106] Fig. 7(a)-(d). The Ni signals

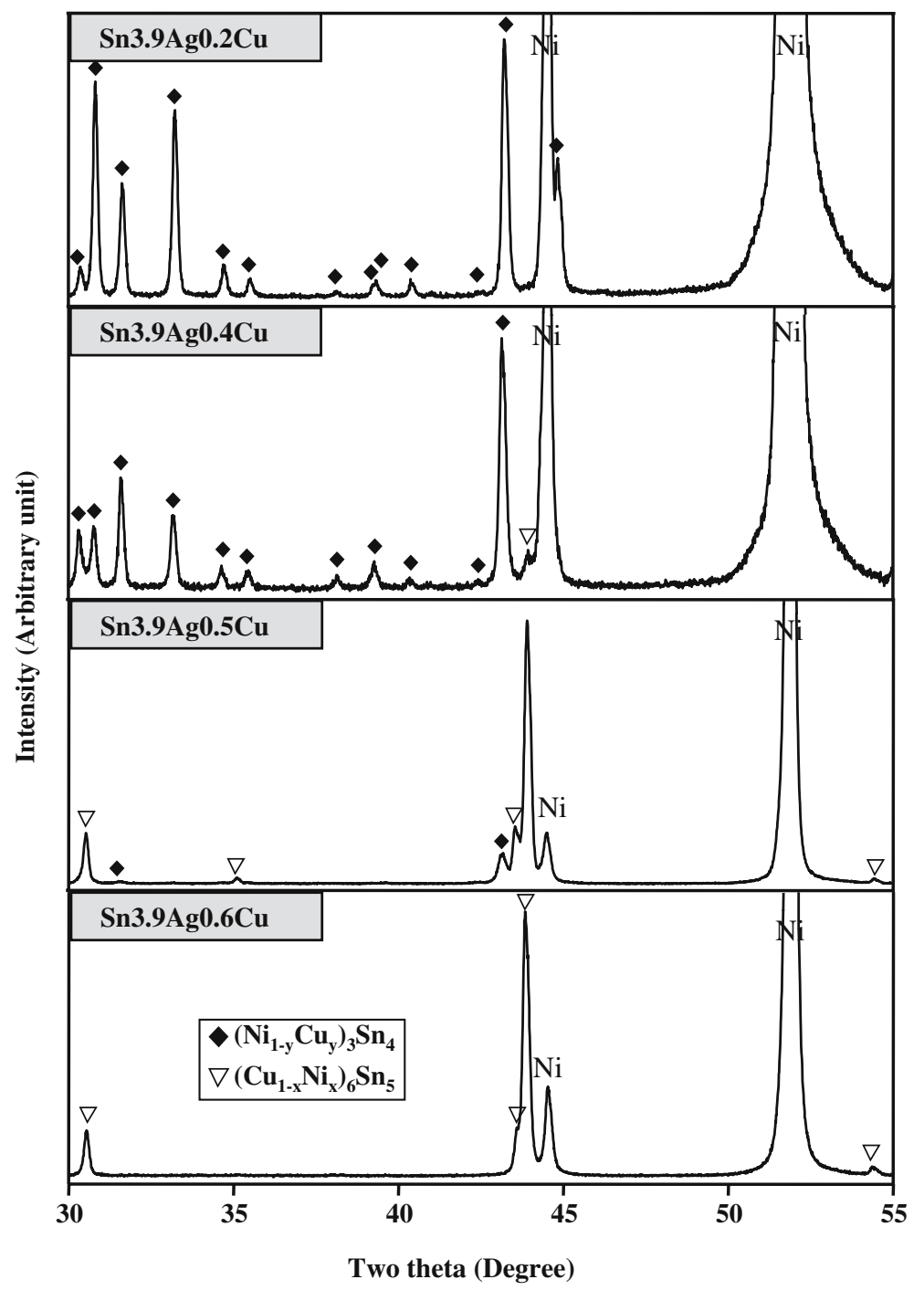

interface becomes dynamic. The volume effect must be considered as the volume of the solder determines the total available $\mathrm{Cu}$. As the size of the joints shrinks, the supply of $\mathrm{Cu}$ becomes more limited, and the decrease in $\mathrm{Cu}$ concentration becomes more critical. Next, the combined effects of the limited $\mathrm{Cu}$ supply (solder volume effect) and the $\mathrm{Cu}$ concentration $(\mathrm{Cu}$ concentration effect) will be presented.

In the reaction between $\mathrm{SnAgCu}$ solder balls and Ni substrate (Fig. 12), the original amount of $\mathrm{Cu}$ in the solder ball before reflow equals the remaining $\mathrm{Cu}$ in the solder plus the $\mathrm{Cu}$ which is incorporated into the intermetallic(s). Neglecting the $\mathrm{Cu}$ atoms in those intermetallic particles located inside the solder, one can obtain the following equation [89-91]:

$W_{\mathrm{Cu}}-W_{\mathrm{Cu}}^{\mathrm{o}} \cong-40 \frac{d_{\text {pad }}^{2}}{d_{\text {joint }}^{3}} T_{\mathrm{IMC}}($ wt. $\%)$ where $W_{\mathrm{Cu}}^{\mathrm{o}}$ and $W_{\mathrm{Cu}}$ represent the $\mathrm{Cu}$ concentration (in wt.\%) in $\mathrm{SnAgCu}$ before reflow and the remaining $\mathrm{Cu}$ concentration after reflow, respectively. The symbols $d_{\text {joint }}$ and $d_{\text {pad }}$ represent the diameters (in $\mu \mathrm{m}$ ) of the solder ball and the pad's opening of the substrate, respectively. The symbol $T_{\text {IMC }}$ represents the thickness (in $\mu \mathrm{m}$ ) of intermetallic compound (IMC) at the interface. The compounds $\left(\mathrm{Cu}_{1-x}\right.$ $\left.\mathrm{Ni}_{x}\right)_{6} \mathrm{Sn}_{5}$ and $\left(\mathrm{Ni}_{1-y} \mathrm{Cu}_{y}\right)_{3} \mathrm{Sn}_{4}$ are the only two $\mathrm{Cu}-$ bearing intermetallics that can be present at the interface, and their compositions had been determined by EPMA to be around $\left(\mathrm{Cu}_{0.60} \mathrm{Ni}_{0.40}\right)_{6} \mathrm{Sn}_{5}$ and $\left(\mathrm{Ni}_{0.80} \mathrm{Cu}_{0.20}\right)_{3} \mathrm{Sn}_{4}$ for those solders with $\mathrm{Cu}$ within 0.4-0.6 wt.\% [73, 75, 87, 89-91]. Here, those $\mathrm{Cu}$ in $\left(\mathrm{Ni}_{1-y} \mathrm{Cu}_{y}\right)_{3} \mathrm{Sn}_{4}$ could be ignored because the thickness of this compound was thin and its $\mathrm{Cu}$ concentration was low ( $\sim 6 \mathrm{wt} . \%)$. The drop of the $\mathrm{Cu}$ concentration according to Eq. 1 for several different ball/pad 

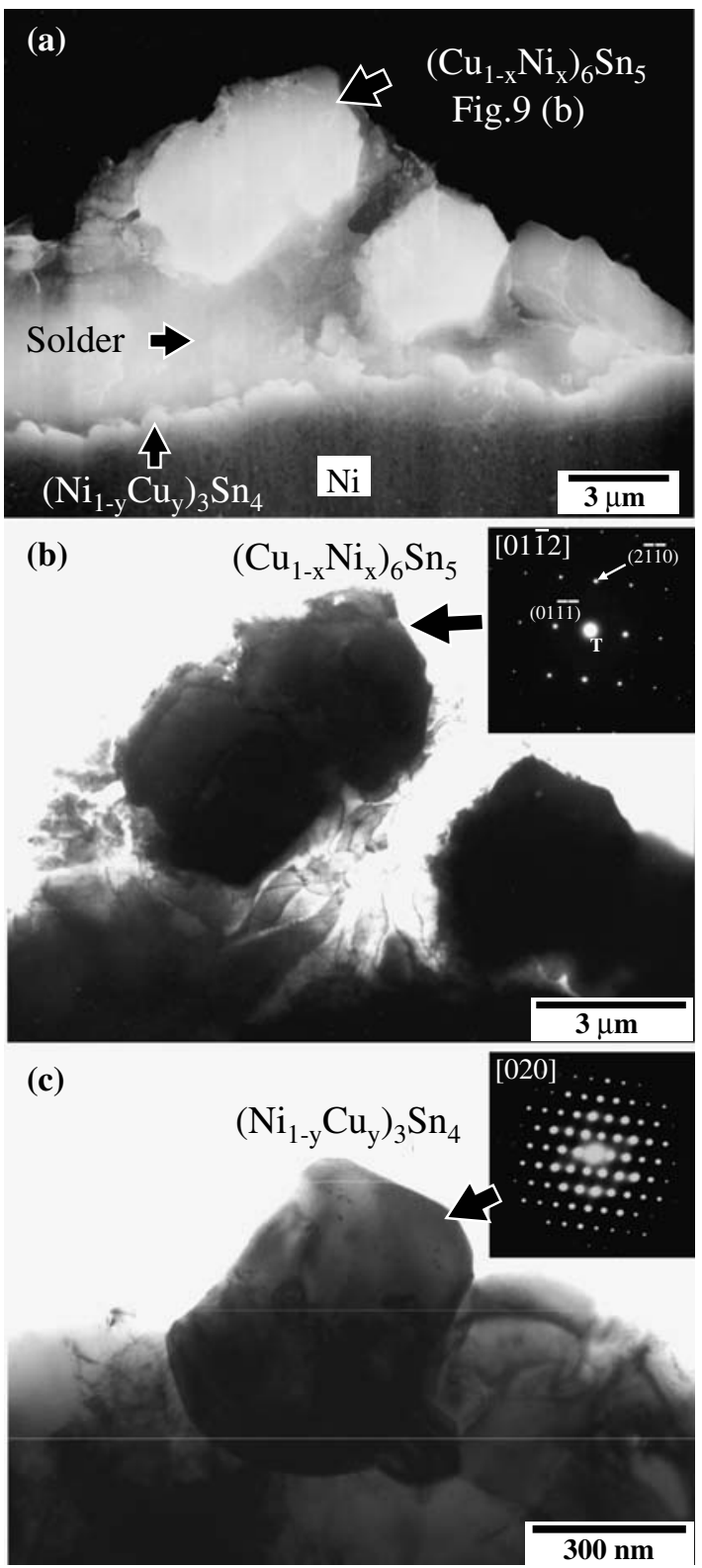

Fig. 9 (a) Scanning electron image showing the reaction zone of Sn3.9Ag $0.4 \mathrm{Cu} / \mathrm{Ni}$ after $250^{\circ} \mathrm{C}$ soldering for $10 \mathrm{~min}$. (b) TEM bright field image of (a) and selected area diffraction pattern of $\left(\mathrm{Cu}_{1-x} \mathrm{Ni}_{x}\right)_{6} \mathrm{Sn}_{5}$. (c) TEM bright field image of (a) and selected area diffraction pattern of $\left(\mathrm{Ni}_{1-y} \mathrm{Cu}_{y}\right)_{3} \mathrm{Sn}_{4}$. [106]

combinations ranging from the BGA to flip-chip dimensions is plotted in Fig. 13. For example, if $2 \mu \mathrm{m}$ $\left(\mathrm{Cu}_{1-x} \mathrm{Ni}_{x}\right)_{6} \mathrm{Sn}_{5}$, which is the thickness commonly seen in real solder joints, forms in the $100 \mu \mathrm{m} / 80 \mu \mathrm{m}$ combination, the $\mathrm{Cu}$ concentration will drop by as large as 0.51 wt.\%. Under such a condition, the residue $\mathrm{Cu}$ concentration in solder will be less than $0.3 \mathrm{wt} \%$ for most $\mathrm{SnAgCu}$ solder compositions listed in Table 1. If the $\mathrm{Cu}$ concentration indeed become less than 0.3 wt. $\%$, then the $\mathrm{Cu}_{6} \mathrm{Sn}_{5} /$ molten solder interface is no longer thermodynamically stable

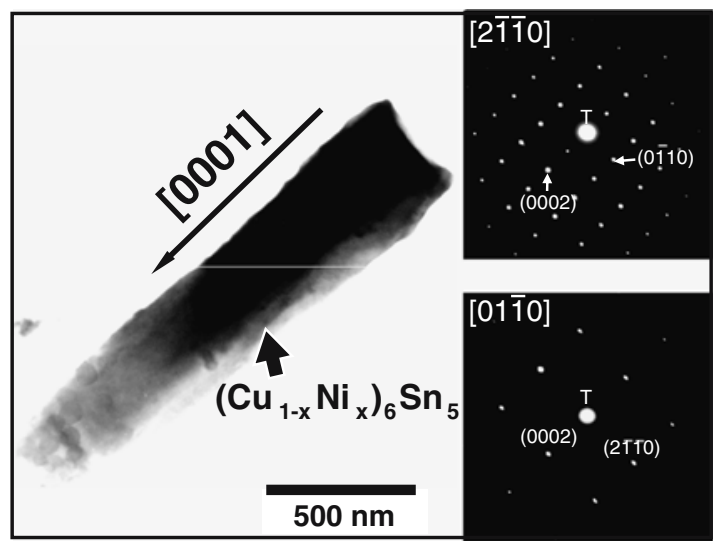

Fig. 10 TEM bright field image and selected area diffraction patterns for a $\left(\mathrm{Cu}_{1-x} \mathrm{Ni}_{x}\right)_{6} \mathrm{Sn}_{5}$ needle shown in Fig. 7(d) [106]

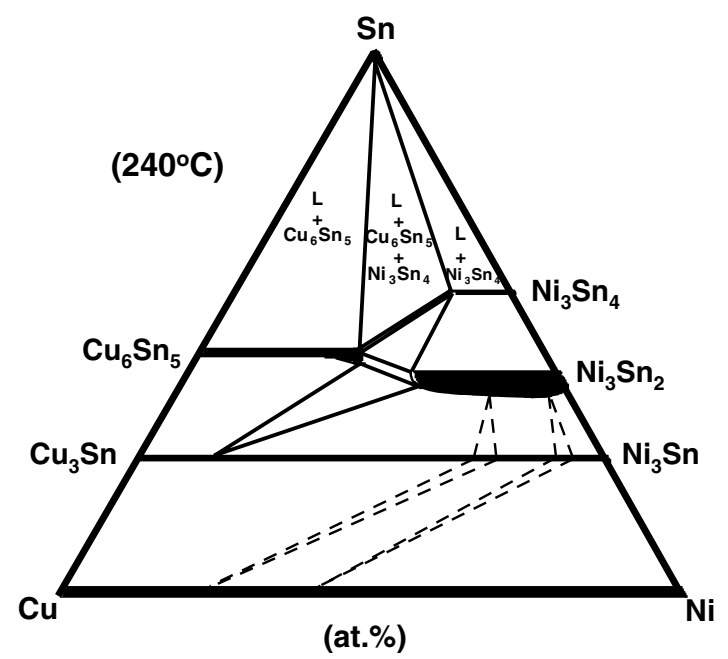

Fig. $11 \mathrm{Cu}-\mathrm{Ni}-\mathrm{Sn}$ isotherm at $240^{\circ} \mathrm{C}$. This isotherm is re-drawn basing on the literature data $[113,114]$

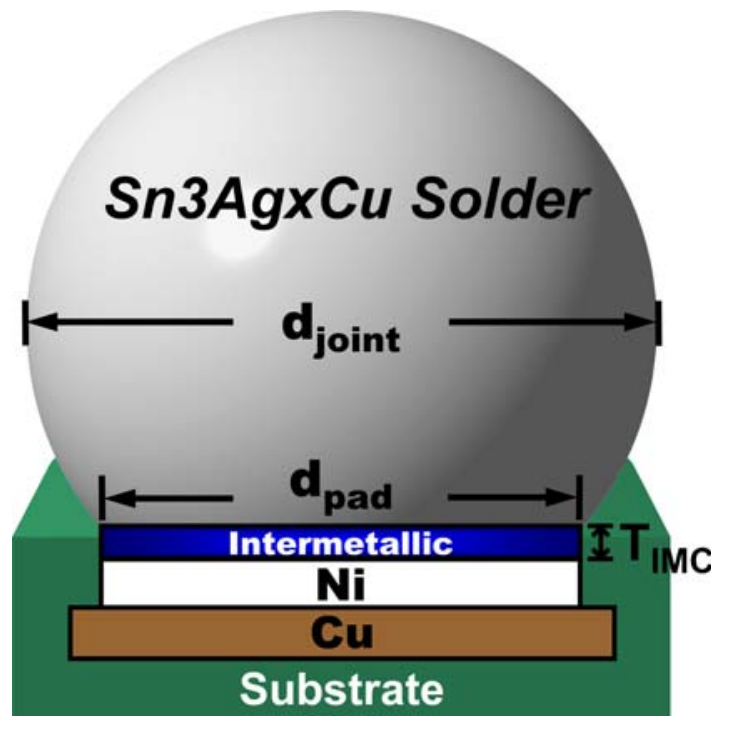

Fig. 12 Schematic diagram showing a $\mathrm{Sn} 3 \mathrm{AgxCu}$ solder ball soldered onto a $\mathrm{Ni} / \mathrm{Cu}$ pad 


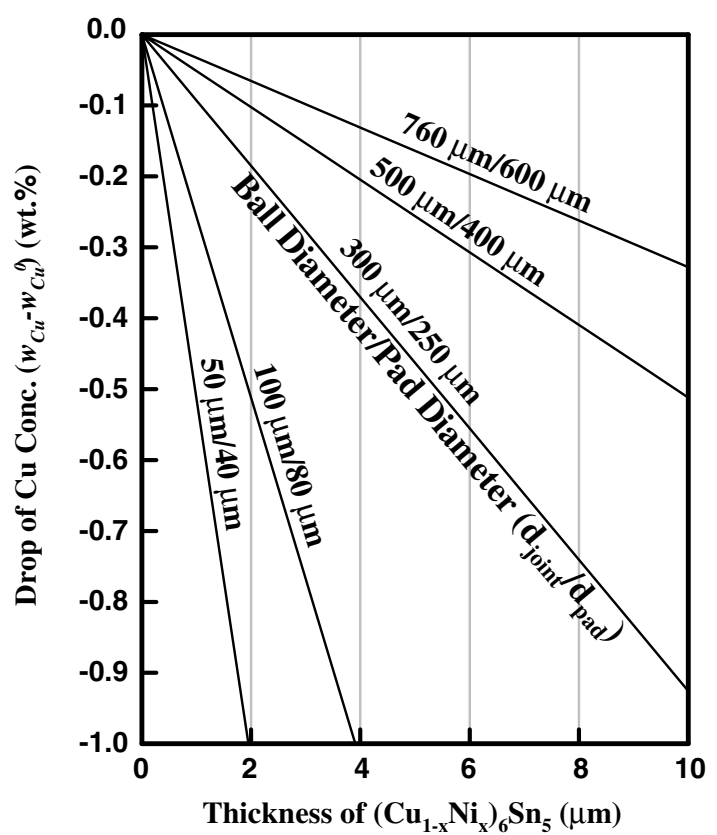

Fig. 13 Drop of $\mathrm{Cu}$ concentration according to Eq. 1 for different $d_{\text {joint }} / d_{\text {pad }}$ combinations

according to Fig. 5. There will be a huge driving force for $\mathrm{Ni}_{3} \mathrm{Sn}_{4}$ [or $\left(\mathrm{Ni}_{1-y} \mathrm{Cu}_{y}\right)_{3} \mathrm{Sn}_{4}$ ] to form.

For BGA or flip-chip joints, the design rule usually calls for the condition that $d_{\text {joint }} \approx 1.2 d_{\text {pad }}$, therefore, the following equation can be obtained from Eq. 1:

$W_{\mathrm{Cu}}-W_{\mathrm{Cu}}^{\mathrm{o}} \approx-28 \frac{T_{\mathrm{IMC}}}{d_{\text {joint }}} \propto \frac{1}{d_{\text {joint }}}$

This joint size dependence can be clearly seen in Fig. 14, where the drop of the $\mathrm{Cu}$ concentration is plotted against the joint size. In short, the $\mathrm{Cu}$ concentration drop rapidly increases as the joint becomes smaller.

Additional experimental evidence of the solder volume effect is presented in Fig. 15 [89-91]. The experimental setup in Fig. 15 was used with $d_{\text {pad }}$ being kept constant at $375 \mu \mathrm{m}$, and $d_{\text {joint }}$ being varied from 760 to 500 , and to $300 \mu \mathrm{m}$. In other words, three different $d_{\text {joint }} / d_{\text {pad }}$ values were used. The solder used here was $\mathrm{Sn} 3 \mathrm{Ag} 0.6 \mathrm{Cu}$, and the samples had been reflowed with a typical profile $\left(235^{\circ} \mathrm{C}\right.$ peak temperature, $90 \mathrm{~s}$ molten solder duration). Using Eq. 1 and the $\left(\mathrm{Cu}_{1-x} \mathrm{Ni}_{x}\right)_{6} \mathrm{Sn}_{5}$ thicknesses measured from the three cases shown in Fig. 15 (1.2, 1.5, and $2.2 \mu \mathrm{m}$, respectively), one can calculate the $\mathrm{Cu}$ concentration drops to be $0.02,0.05$, and 0.48 wt. $\%$ for 760,500 , and $300 \mu \mathrm{m} d_{\text {joint }}$, respectively. As a result, the remaining $\mathrm{Cu}$ concentrations of the solders after reflow were $0.58,0.55$, and 0.12 wt. $\%$ for $d_{\text {joint }}=760,500$, and $300 \mu \mathrm{m}$, respectively. As expected, the intermetallic compound for the first two cases shown in Fig. 15(a) and (b) was still

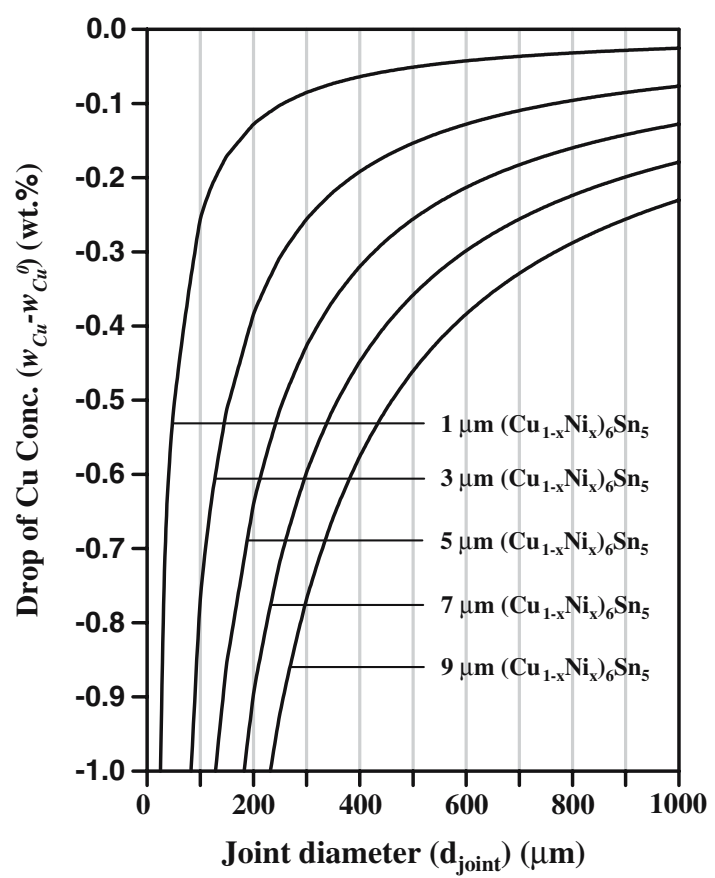

Fig. 14 Drop of $\mathrm{Cu}$ concentration according to Eq. 2 for different $d_{\text {joint }}$

$\left(\mathrm{Cu}_{1-x} \mathrm{Ni}_{x}\right)_{6} \mathrm{Sn}_{5}$. However, for the $300 \mu \mathrm{m}$ case, the $\mathrm{Cu}$ concentration was so low that a new layer of $\left(\mathrm{Ni}_{1-}\right.$ $\left.{ }_{y} \mathrm{Cu}_{y}\right)_{3} \mathrm{Sn}_{4}$ had nucleated beneath the $\left(\mathrm{Cu}_{1-x} \mathrm{Ni}_{x}\right)_{6} \mathrm{Sn}_{5}$ layer that formed in the early stage of the reaction when the $\mathrm{Cu}$ concentration was still high. In Fig. 15(c), a series of voids can be seen, separating these two intermetallic compounds. As will be shown in the next section, an advanced development, when the reflow time is increased longer (see Fig. 18) or the solder joint is shrunk even smaller (see Fig. 17), of this effect is the total separation (spalling) of the upper $\left(\mathrm{Cu}_{1-x} \mathrm{Ni}_{x}\right)_{6} \mathrm{Sn}_{5}$ layer from the interface. That is, the consequence of the shifting equilibrium phase leads to the massive spalling of $\left(\mathrm{Cu}_{1-x} \mathrm{Ni}_{x}\right)_{6} \mathrm{Sn}_{5}$.

In summary, in the reaction between $\mathrm{Ni}$ substrate and the $\mathrm{SnAgCu}$ solder with a small volume, the supply of $\mathrm{Cu}$ becomes a problem. Under such conditions, the $\mathrm{Cu}$ concentration is no longer constant during the reaction. In fact, it is possible that the interface experiences several phase equilibrium conditions during the course of the reaction. This solder volume effect is more severe for smaller solder joints and for joints with a thicker $\left(\mathrm{Cu}_{1-x} \mathrm{Ni}_{x}\right)_{6} \mathrm{Sn}_{5}$ at the interface (i.e., joints with a longer reaction time).

\subsection{Massive spalling of intermetallic compound from the interface}

Spalling refers to the detachment of a compound from the interface into one of the reacting phases. One 

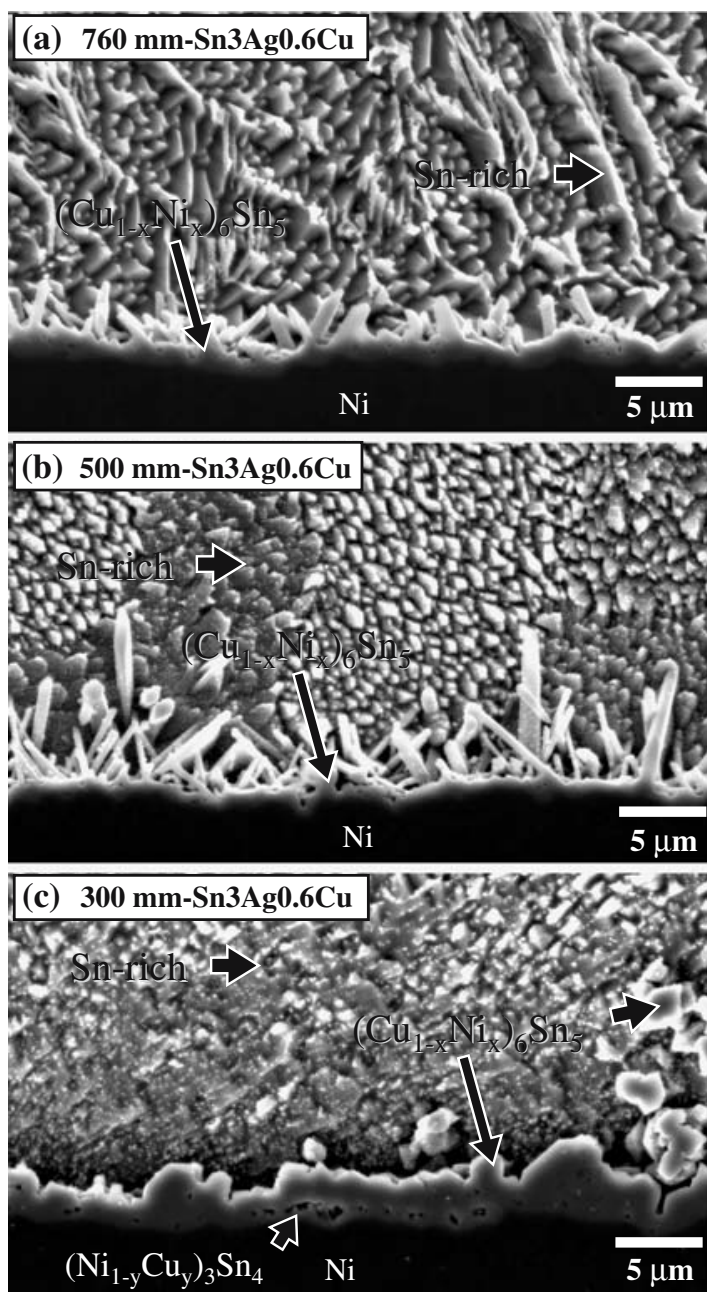

Fig. 15 Micrographs showing the interface after a typical reflow. The value of $d_{\text {pad }}$ was kept constant at $375 \mu \mathrm{m}$, and $d_{\text {joint }}$ was $760 \mu \mathrm{m}$ (a), $500 \mu \mathrm{m}$ (b), and $300 \mu \mathrm{m}$ (c). The solder was 96.4Sn3Ag0.6Cu (wt.\%). [89-91]

classical example, shown in Fig. 16, is the spalling of $\mathrm{Cu}_{6} \mathrm{Sn}_{5}$ during the reaction of eutectic $\mathrm{PbSn}$ solder with $\mathrm{Au} / \mathrm{Cu} / \mathrm{Cu}-\mathrm{Cr}$ thin film $[3,116]$. Spalling here was due to the exhaustion of the $\mathrm{Cu}$ film, and the poor wetting between $\mathrm{Cu}_{6} \mathrm{Sn}_{5}$ and the remaining $\mathrm{Cr}$ (or $\mathrm{SiO}_{2}$ ) caused the compound to detach itself from the interface. The "massive spalling' introduced in this section is not caused by the exhaustion of a reaction layer. Instead, it is caused by the consumption of one element inside the reacting phase, as had been discussed in the previous section. The shifting of the interfacial equilibrium causes the product phase to separate itself from the interface [89-91].

The massive spalling has a higher tendency to occur in smaller joints because these joints will experience a lager $\mathrm{Cu}$ concentration drop. Fig. 17 shows an example of massive spalling in its early stage. The reflow con-

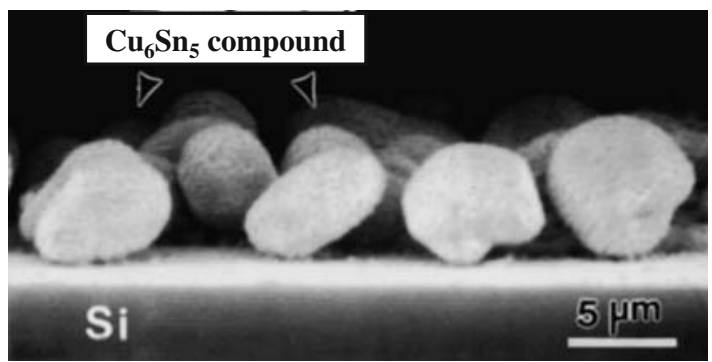

Fig. 16 SEM image showing the spalling of $\mathrm{Cu}_{6} \mathrm{Sn}_{5}$ during the reaction between eutectic $\mathrm{SnPb}$ and $\mathrm{Au} / \mathrm{Cu} / \mathrm{Cu}-\mathrm{Cr}$ substrate $[3,116]$

ditions were the same as those in Fig. 15, but $d_{\text {pad }}$ and $d_{\text {joint }}$ were 175 and $200 \mu \mathrm{m}$, respectively. As can be seen in Fig. 17, a new $\left(\mathrm{Ni}_{1-y} \mathrm{Cu}_{y}\right)_{3} \mathrm{Sn}_{4}$ layer had formed over the $\mathrm{Ni}$ substrate, pushing the original $\left(\mathrm{Cu}_{1-x}\right.$ $\left.\mathrm{Ni}_{x}\right)_{6} \mathrm{Sn}_{5}$ layer away from the interface, and a gap had appeared between these two layers. It should be stressed again that even though the reflow conditions were the same, such spalling did not occur for the larger joints in Fig. 15(a) and (b). Longer reflow time also favors the spalling, as shown in Fig. 18. Here, the sample had the same configuration as that of Fig. 15(c), but the reflow time was increased from $90 \mathrm{~s}$ to $20 \mathrm{~min}$. Longer reflow time had increased the separation between $\left(\mathrm{Ni}_{1-y} \mathrm{Cu}_{y}\right)_{3} \mathrm{Sn}_{4}$ and $\left(\mathrm{Cu}_{1-x} \mathrm{Ni}_{x}\right)_{6} \mathrm{Sn}_{5}$ from a series of voids in Fig. 15(c) to a gap in Fig. 18.

A very revealing example of the massive spalling is shown in Fig. 19, where a $d_{\text {joint }} / d_{\text {pad }}=760 \mu \mathrm{m} / 600 \mu \mathrm{m}$ joint had been reflowed at $235^{\circ} \mathrm{C}$ for $5 \mathrm{~min}$. In this
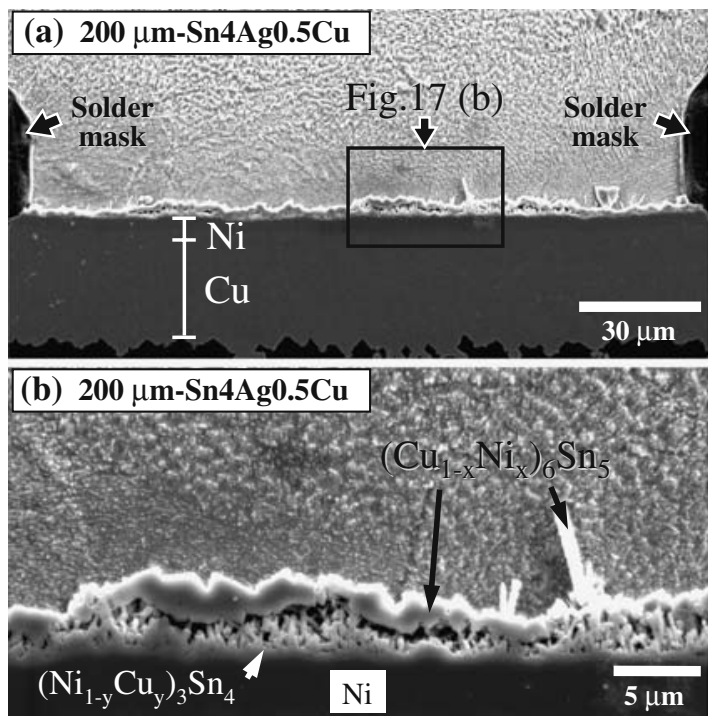

Fig. 17 (a) Massing spalling of $\left(\mathrm{Cu}_{1-x} \mathrm{Ni}_{x}\right)_{6} \mathrm{Sn}_{5}$ after a typical reflow $\left(235^{\circ} \mathrm{C}\right.$ peak temperature, $90 \mathrm{~s}$ molten solder duration) in a solder joint with $d_{\text {joint }} / d_{\text {pad }}=200 \mu \mathrm{m} / 175 \mu \mathrm{m}$. (b) Zoom-in view of (a). [91] 

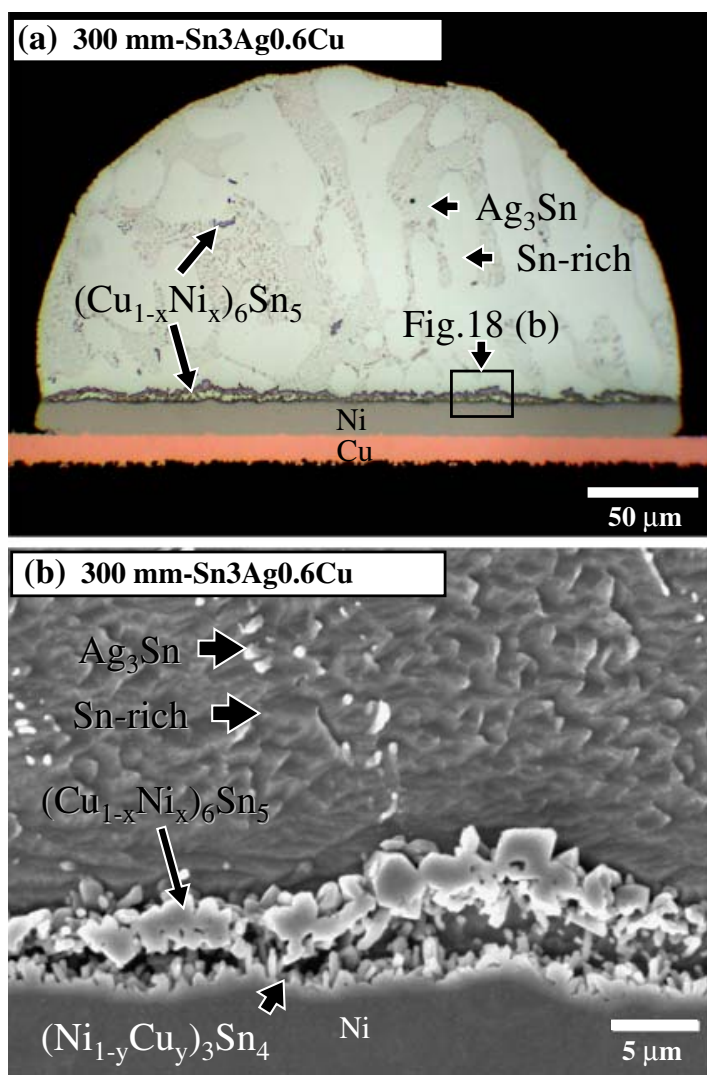

Fig. 18 (a) Massing spalling of $\left(\mathrm{Cu}_{1-x} \mathrm{Ni}_{x}\right)_{6} \mathrm{Sn}_{5}$ after reflow at $235^{\circ} \mathrm{C}$ for $20 \mathrm{~min}$ in a solder joint with $d_{\text {joint }} / d_{\text {pad }}=300 \mathrm{~m} /$ $375 \mu \mathrm{m}$. (b) Zoom-in view of (a). [89-91]

particular sample, a 1.2( \pm 0.1$) \mu \mathrm{m}$ Au layer had been coated over the Ni layer of the substrate before reflow. The images in Fig. 19(a) and (b) were obtained from the same specimen, but the solder in Fig. 19(b) had been etched away. As can be seen here, the detached Au-bearing $\left(\mathrm{Cu}_{1-x} \mathrm{Ni}_{x}\right)_{6} \mathrm{Sn}_{5}$ layer was almost continuously. The extensive spalling shown in this pair of micrographs demonstrates the justification of naming the phenomenon massive spalling. It should be pointed out that our recent data suggests that Au does have the effect of stimulate early massive spalling. More studies are needed to clarify this effect.

There are two approaches to inhibit the massive spalling during reflow. The first is to use solders with a higher $\mathrm{Cu}$ concentration. The second method is to provide an infinite $\mathrm{Cu}$ source, such as a thick $\mathrm{Cu}$ layer on either side of a solder joint [89-91]. Our latest results also supported this view.

\subsection{Solder volume effect during reaction with solid solders (aging)}

The solder volume effect also plays an important role during the solid-state aging. Fig. 20 shows the solder
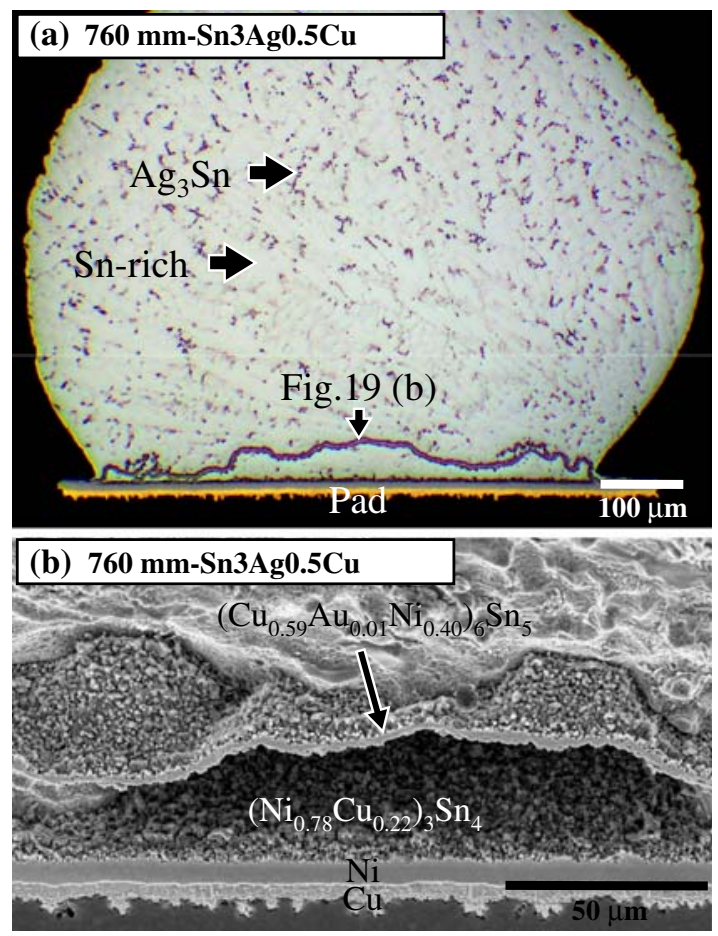

Fig. 19 (a) Cross-section view of a solder joint that had been

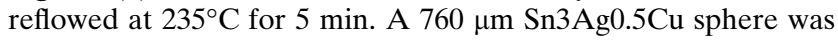
attached to a $600 \mu \mathrm{m}$ pad with the $\mathrm{Au}(1.2 \mu \mathrm{m}) / \mathrm{Ni}$ surface finish. (b) Zoom-in view of (a) after etching away the solder. This micrograph had been tilted $45^{\circ}$

joints with the same reflow conditions $\left(235^{\circ} \mathrm{C}\right.$ peak temperature, $90 \mathrm{~s}$ molten solder duration), the same aging conditions $\left(160^{\circ} \mathrm{C}\right.$ for $\left.1,000 \mathrm{~h}\right)$, and the same $d_{\text {pad }}$ value $(375 \mu \mathrm{m})$, but with different $d_{\text {joint }}$ values and different $\mathrm{Cu}$ compositions in solder. When the joint was relatively large $(760 \mu \mathrm{m})$, the only intermetallic compound at the interface was $\left(\mathrm{Cu}_{1-x}\right.$ $\left.\mathrm{Ni}_{x}\right)_{6} \mathrm{Sn}_{5}$ for all the solder compositions, as shown in Fig. 20(a)-(c). This is due to the fact that the supply of $\mathrm{Cu}$ was relatively abundant for the larger solder joints.

For the solder joints with the medium diameter $(500 \mu \mathrm{m})$, the supply of $\mathrm{Cu}$ became somewhat limited. There was still only the $\left(\mathrm{Cu}_{1-x} \mathrm{Ni}_{x}\right)_{6} \mathrm{Sn}_{5}$ layer at the interface if the joint's $\mathrm{Cu}$ concentration was high enough (0.5 and 0.7 wt.\%), as shown in Fig. 20(d) and (e). But when the applied $\mathrm{Cu}$ concentration became very low (0.3 wt.\%), as shown in Fig. 20(f), a layer of $\left(\mathrm{Ni}_{1-y} \mathrm{Cu}_{y}\right)_{3} \mathrm{Sn}_{4}$ formed beneath $\left(\mathrm{Cu}_{1-x} \mathrm{Ni}_{x}\right)_{6} \mathrm{Sn}_{5}$. Given more time, the remaining $\left(\mathrm{Cu}_{1-x} \mathrm{Ni}_{x}\right)_{6} \mathrm{Sn}_{5}$ will also disappear, leaving $\left(\mathrm{Ni}_{1-y} \mathrm{Cu}_{y}\right)_{3} \mathrm{Sn}_{4}$ as the only layer. This is because the $\mathrm{Cu}$ atoms in $\left(\mathrm{Cu}_{1-x} \mathrm{Ni}_{x}\right)_{6} \mathrm{Sn}_{5}$ are extracted out to form more $\left(\mathrm{Ni}_{1-y} \mathrm{Cu}_{y}\right)_{3} \mathrm{Sn}_{4}$.

When the solder joints became even smaller $(300 \mu \mathrm{m})$, the supply of $\mathrm{Cu}$ became very limited. For 


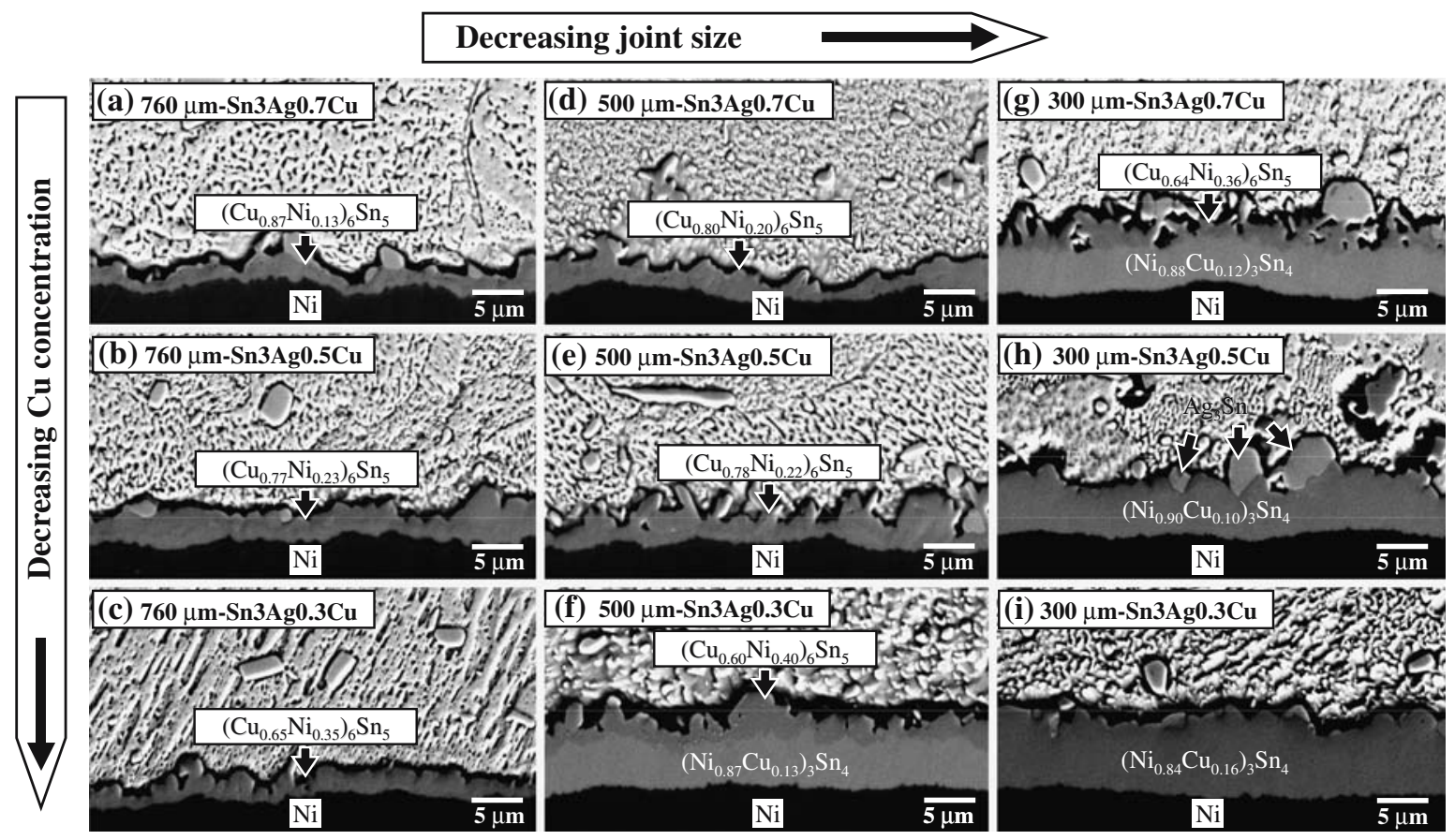

Fig. 20 Micrographs showing solder joints with the same reflow conditions $\left(235^{\circ} \mathrm{C}\right.$ peak temperature, $90 \mathrm{~s}$ molten solder duration), the same aging conditions $\left(160^{\circ} \mathrm{C}\right.$ for $\left.1,000 \mathrm{~h}\right)$, and the same $d_{\text {pad }}$ value $(375 \mu \mathrm{m})$, but with different $d_{\text {joint }}$ values and

the joint with the highest $\mathrm{Cu}$ concentration (0.7 wt.\%), shown in Fig. 20(g), the amount of $\mathrm{Cu}$ was still enough to sustain a $\left(\mathrm{Cu}_{1-x} \mathrm{Ni}_{x}\right)_{6} \mathrm{Sn}_{5}$ layer over the $\left(\mathrm{Ni}_{1-y}\right.$ $\left.\mathrm{Cu}_{y}\right)_{3} \mathrm{Sn}_{4}$, as shown in Fig. $20(\mathrm{~g})$. But when the $\mathrm{Cu}$ concentration became lower $(0.5$ and $0.3 \mathrm{wt} \% \mathrm{Cu})$, shown in Fig. 20(h) and (i), the amount of $\mathrm{Cu}$ was not enough to sustain the $\left(\mathrm{Cu}_{1-x} \mathrm{Ni}_{x}\right)_{6} \mathrm{Sn}_{5}$ layer, and only a $\left(\mathrm{Ni}_{1-y} \mathrm{Cu}_{y}\right)_{3} \mathrm{Sn}_{4}$ layer was present. It should be noted that in these two cases $\left(\mathrm{Cu}_{1-x} \mathrm{Ni}_{x}\right)_{6} \mathrm{Sn}_{5}$ did appear over the $\left(\mathrm{Ni}_{1-y} \mathrm{Cu}_{y}\right)_{3} \mathrm{Sn}_{4}$ layer once during certain time frame, but $\left(\mathrm{Cu}_{1-x} \mathrm{Ni}_{x}\right)_{6} \mathrm{Sn}_{5}$ eventually disappeared and be converted into $\left(\mathrm{Ni}_{1-y} \mathrm{Cu}_{y}\right)_{3} \mathrm{Sn}_{4}$. It can be anticipated that the $\left(\mathrm{Cu}_{1-x} \mathrm{Ni}_{x}\right)_{6} \mathrm{Sn}_{5}$ layer in Fig. $20(\mathrm{~g})$ will also disappear if this sample is subjected to longer aging.

From our recent study, the formation of both $\left(\mathrm{Ni}_{1-y} \mathrm{Cu}_{y}\right)_{3} \mathrm{Sn}_{4}$ and $\left(\mathrm{Cu}_{1-x} \mathrm{Ni}_{x}\right)_{6} \mathrm{Sn}_{5}$ layers at the interface after aging has a negative impact on the strength of the joints. The joints tend to fail along the interface of these two compounds. This is because both these two compounds are quite brittle, and the interface between two brittle intermetallics unfortunately tends to be weak, especially for two compounds originate from two different binary systems. To avoid the formation of two compounds simultaneously, both the $\mathrm{Cu}$ concentration effect and the solder volume effect have to be taken into account at the same time. different $\mathrm{Cu}$ compositions. Pictures in the first, second, and third row have $\mathrm{Cu}$ concentrations equal $0.7,0.5$, and 0.3 wt.\%, respectively. Pictures in the first, second, and third column have $d_{\text {joint }}$ equal 760,500 , and $300 \mu \mathrm{m}$, respectively

\section{Cross-interaction between $\mathrm{Cu}$ and $\mathrm{Ni}$ across a solder joint}

In Sects. 2 and 3, the effect of $\mathrm{Ni}$ on the reaction between $\mathrm{Cu}$ and solder and the effect of $\mathrm{Cu}$ on the reaction between $\mathrm{Ni}$ and solder are discussed, respectively. In this section, the interaction between $\mathrm{Cu}$ and $\mathrm{Ni}$ across a solder joint will be considered. The importance of such cross-interaction had been reported in several publications available in the literature [53, 80, 117-120].

\subsection{Cross-interaction during reaction with molten solders (reflow)}

To investigate the cross-interaction during the reflow stage more carefully, the solder joints that were assembled by two different paths are compared. As illustrated in Fig. 21, in Path I, the solder (Sn3.5Ag) was attached to the $\mathrm{Cu}$ substrate in the first reflow, and then the Ni substrate was attached to the other side of the solder joint in the second reflow. In path II, the solder was attached to the Ni substrate first (the first reflow), and in the second reflow $\mathrm{Cu}$ substrate was attached to the other side of the solder joint.

Shown in Fig. 22 are the solder/Cu and Ni/solder interfaces for Path I (left column) and path II (right 


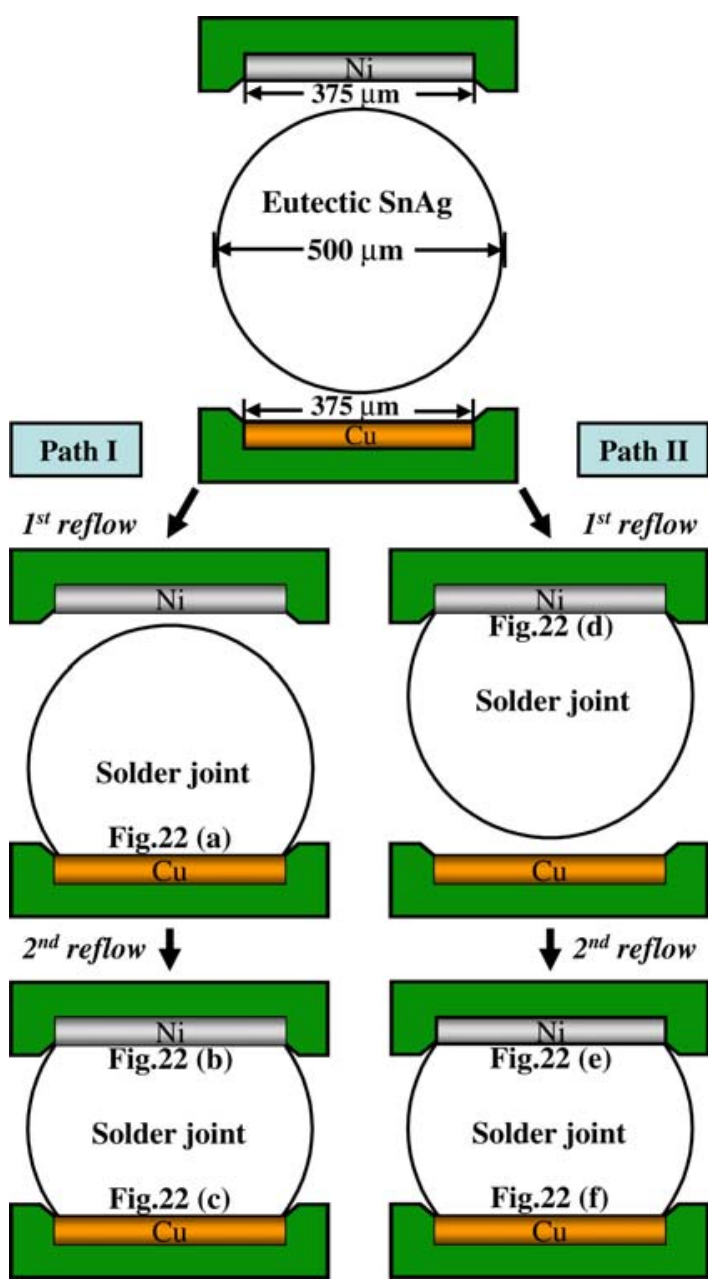

Fig. 21 Illustration showing the two sequences that the solder joints were assembled

column) after the first reflow, and the second reflow. For Path I, the solder/Cu interface after the first reflow, Fig. 22(a), is typical of the reaction between $\mathrm{Cu}$ and Sn-based solders: formation of $\mathrm{Cu}_{6} \mathrm{Sn}_{5}$ scallops along the interface. A typical reflow actually dissolves a large quantity of $\mathrm{Cu}$ from the substrate. Our own data shows that as high as $7.5( \pm 0.3) \mu \mathrm{m}$ of $\mathrm{Cu}$ can be dissolved into the $\mathrm{Sn} 3.5 \mathrm{Ag}$ during a typical reflow $(90 \mathrm{~s}$ reflow time with a peak temperature of $235^{\circ} \mathrm{C}$ of a $760 \mu \mathrm{m}$ BGA joint, making the $\mathrm{Cu}$ concentration in solder become as high as $\sim 1.2$ wt. $\%$. These dissolved $\mathrm{Cu}$ atoms precipitated out as long $\mathrm{Cu}_{6} \mathrm{Sn}_{5}$ rods inside the solder when the solder solidified, as shown in Fig. 23. During the second reflow of Path I, the dissolved $\mathrm{Cu}$ atoms had an effect on the $\mathrm{Ni} /$ solder reaction. As shown in Fig. 22(b), the reaction product under such conditions was $\left(\mathrm{Cu}_{0.89} \mathrm{Ni}_{0.11}\right)_{6} \mathrm{Sn}_{5}$. This microstructure shows marked difference with that of Fig. 22(d), which shows fresh $\mathrm{Sn} 3.5 \mathrm{Ag}$ soldered over the Ni substrate. The second reflow also influenced the solder/Cu interface. As shown in Fig. 22(c), a small amount of Ni ( 2 at.\%) can be detected in $\mathrm{Cu}_{6} \mathrm{Sn}_{5}$. The only $\mathrm{Ni}$ source was from the Ni substrate. This result clearly shows that during the second reflow $\mathrm{Ni}$ had the capacity to have itself dissolved at the $\mathrm{Ni} /$ solder interface, migrate across the solder joint, and incorporate itself into $\mathrm{Cu}_{6} \mathrm{Sn}_{5}$. Nevertheless, the amount of $\mathrm{Ni}$ that was able to reach the solder/Cu interface, it was apparently not large enough to cause the effect described in Sect. 2.2. In short, during the assembly of a $\mathrm{Cu} /$ solder/Ni solder joint through Path I, the two interfaces can crossinteract during the reflow stage.

For Path II after the first reflow, a thin layer of $\mathrm{Ni}_{3} \mathrm{Sn}_{4}$ formed at the $\mathrm{Ni}$ /solder interface, as shown in Fig. 22(d). A small amount of $\mathrm{Ni}$ also dissolved into the molten solder. During the second reflow, the dissolved $\mathrm{Ni}$ atoms had an effect on the solder/Cu reaction. As shown in Fig. 22(f), the reaction product at the solder/ $\mathrm{Cu}$ interface had two distinct regions with their own compositions, $\left(\mathrm{Cu}_{0.81} \mathrm{Ni}_{0.19}\right)_{6} \mathrm{Sn}_{5}$ and $\left(\mathrm{Cu}_{0.93} \mathrm{Ni}_{0.07}\right)_{6} \mathrm{Sn}_{5}$. This microstructure is the same as that shown in Fig. 4(b). Apparently, the reflow condition was sufficient to dissolve enough amount of $\mathrm{Ni}$ into solder to produce the Ni effect as discussed in Sect. 2.2. Quite surprisingly, the dissolved $\mathrm{Cu}$ during its fist reflow (i.e., the second reflow in path II) was also high enough to induce the $\mathrm{Cu}$ concentration effect. As shown in Fig. 22(e), the outer intermetallic at the $\mathrm{Ni} /$ solder interface had changed from $\mathrm{Ni}_{3} \mathrm{Sn}_{4}$ to $\left(\mathrm{Cu}_{1-x} \mathrm{Ni}_{x}\right)_{6} \mathrm{Sn}_{5}$. This fast transformation from one compound to another in time as short as $90 \mathrm{~s}$ does not seem reasonable. A careful cutting by using the focused ion beam (FIB) technique was able to show that this transformation was indeed fast, but was not complete. As shown in Fig. 24, there was a very thin layer of $\left(\mathrm{Ni}_{1-y} \mathrm{Cu}_{y}\right)_{3} \mathrm{Sn}_{4}$ beneath the $\left(\mathrm{Cu}_{1-x} \mathrm{Ni}_{x}\right)_{6} \mathrm{Sn}_{5}$ layer. The FIB technique was also applied to other interface of Fig. 22, but only one type of intermetallic was observed. As shown in Fig. 25, the crystal structures of the $\mathrm{Ni}_{3} \mathrm{Sn}_{4}$ compound and the $\mathrm{Cu}_{6} \mathrm{Sn}_{5}$-based compound in Fig. 22(d) and (e) had also been positively identified by the glancing angle XRD measurements.

Comparing Path I and II, one can conclude that even the sequence of assembly has an effect on the intermetallic microstructures.

\subsection{Cross-interaction during reaction with solid solders (aging)}

Figure 26 shows the microstructures of the interfaces in Fig. 22 after aging at $160^{\circ} \mathrm{C}$ for $1,000 \mathrm{~h}$. The $\mathrm{Ni} /$ solder interface and the solder/Cu interface that had 
Fig. 22 Micrographs showing the solder/Cu and $\mathrm{Ni} /$ solder interfaces for Path I (left column) and path II (right column) illustrated in Fig. 21. The micrographs in (a) and (d) had been tilted by $30^{\circ}$
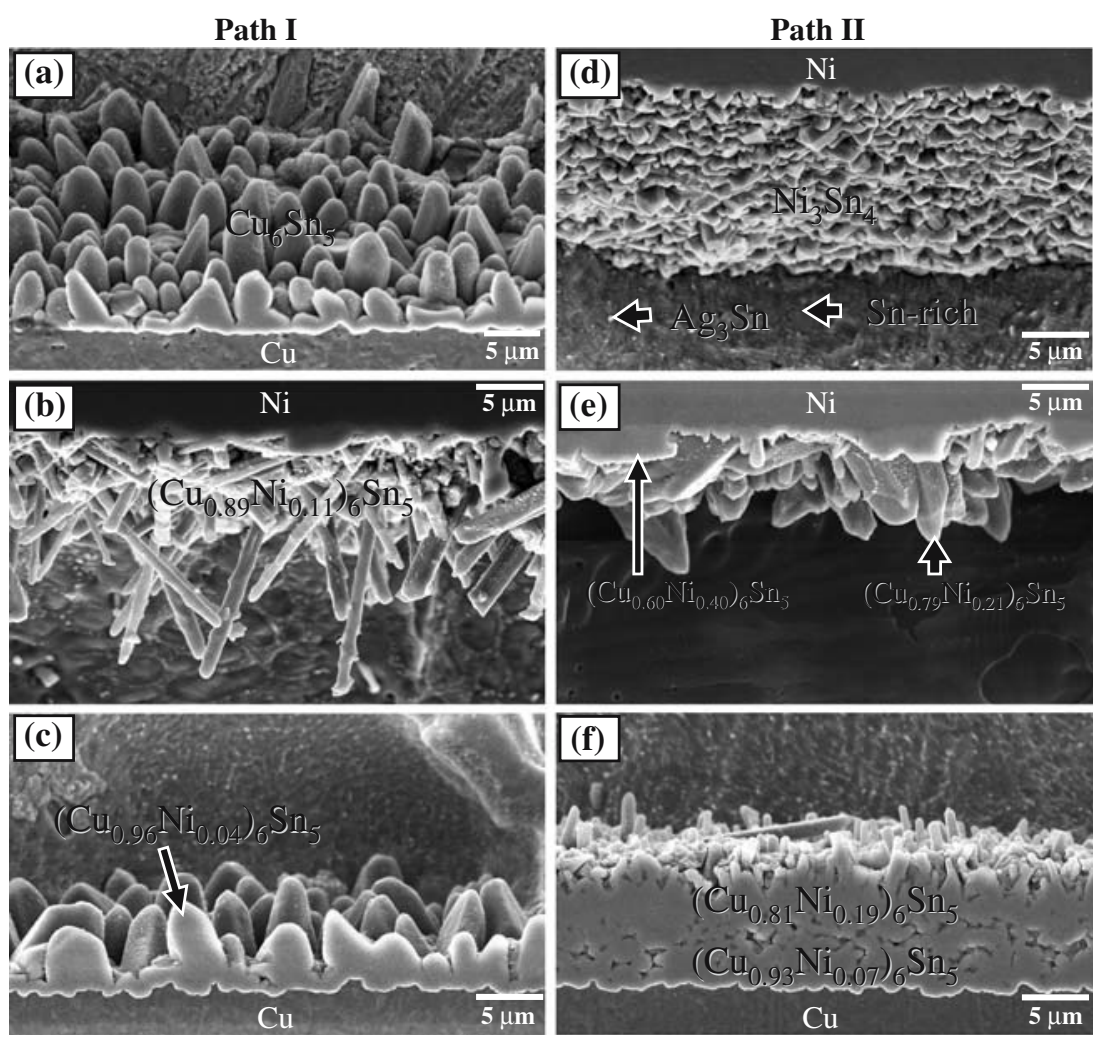

been soldered only once and consequently had no cross-interaction during aging were shown in the left column for comparison. In the middle column and the right column, the corresponding interfaces for the Path I and Path II after aging are shown, respectively. It can be seen that $\mathrm{Cu}_{3} \mathrm{Sn}$ in Fig. 26(d) and (f) are thinner than that in Fig. 26(b). This is due to the Ni effect presented in Sect. 2.2. Moreover, $\mathrm{Cu}_{3} \mathrm{Sn}$ in Fig. 26(f) is also thinner than that in Fig. 26(d). This is reasonable because in Path II more Ni was dissolved because Ni in Path II went through one more reflow than in Path I. In addition, no Kirkendall void was observed in Fig. 26(d) and (f) even by the means of FIB sample preparation. It should also be pointed that the cross-interaction accelerated the consumption rate of the $\mathrm{Cu}$ substrate and reduced the consumption rate of the Ni substrate [120]. The Ni consumption rate decreased because the growth of $\left(\mathrm{Cu}_{1-x} \mathrm{Ni}_{x}\right)_{6} \mathrm{Sn}_{5}$ consumed a less amount of $\mathrm{Ni}$ than did the growth of $\left(\mathrm{Ni}_{1-y} \mathrm{Cu}_{y}\right)_{3} \mathrm{Sn}_{4}[81,107,117$, 120].

\section{Summary}

The addition of $\mathrm{Ni}$ to $\mathrm{Sn}, \mathrm{SnCu}, \mathrm{SnAg}$, and $\mathrm{SnAgCu}$ in amounts as minute as $0.1 \mathrm{wt} \%$ is able to substantially hinder the $\mathrm{Cu}_{3} \mathrm{Sn}$ growth in the reaction between these solders and the $\mathrm{Cu}$ substrate. The growth of $\mathrm{Cu}_{3} \mathrm{Sn}$ often accompanies the formation of Kirkendall voids, which has been linked to the weakening of the solders joints. Accordingly, Ni has been proposed as a useful alloying additive to these solders.

Likewise, $\mathrm{Cu}$ has a strong effect on the reactions between these solders and Ni-based substrates. When the amount of solder is large so that the supply of $\mathrm{Cu}$ is not an issue, the interfacial reaction is dictated by the $\mathrm{Cu}-\mathrm{Ni}-\mathrm{Sn}$ phase equilibrium, and the types of the reaction products formed depend on the $\mathrm{Cu}$ concentration. Under such a condition, when the $\mathrm{Cu}$ concentration is low ( $\leq 0.3 \mathrm{wt} \%$ ), only $\left(\mathrm{Ni}_{1-y} \mathrm{Cu}_{y}\right)_{3} \mathrm{Sn}_{4}$ forms at the interface. When the $\mathrm{Cu}$ concentration increases to 0.4-0.5 wt.\%, both $\left(\mathrm{Ni}_{1-y} \mathrm{Cu}_{y}\right)_{3} \mathrm{Sn}_{4}$ and $\left(\mathrm{Cu}_{1-x} \mathrm{Ni}_{x}\right)_{6} \mathrm{Sn}_{5}$ form. When the $\mathrm{Cu}$ concentration increases above 0.5 wt. \%, $\left(\mathrm{Cu}_{1-x} \mathrm{Ni}_{x}\right)_{6} \mathrm{Sn}_{5}$ forms. However, in BGA or flip-chip solder joints, where the solder joints are small and the $\mathrm{Cu}$ supply becomes limited, the solder volume effect becomes important because the $\mathrm{Cu}$ concentration is no longer constant during the reaction. An equation, Eq. 1, for the $\mathrm{Cu}$ concentration drop has been derived as a function of the joint size and the intermetallic compound thickness. As the $\mathrm{Cu}$ concentration decreases, the equilibrium phase at the interface may change, and the local thermodynamic equilibrium at the interface is no longer static. The 

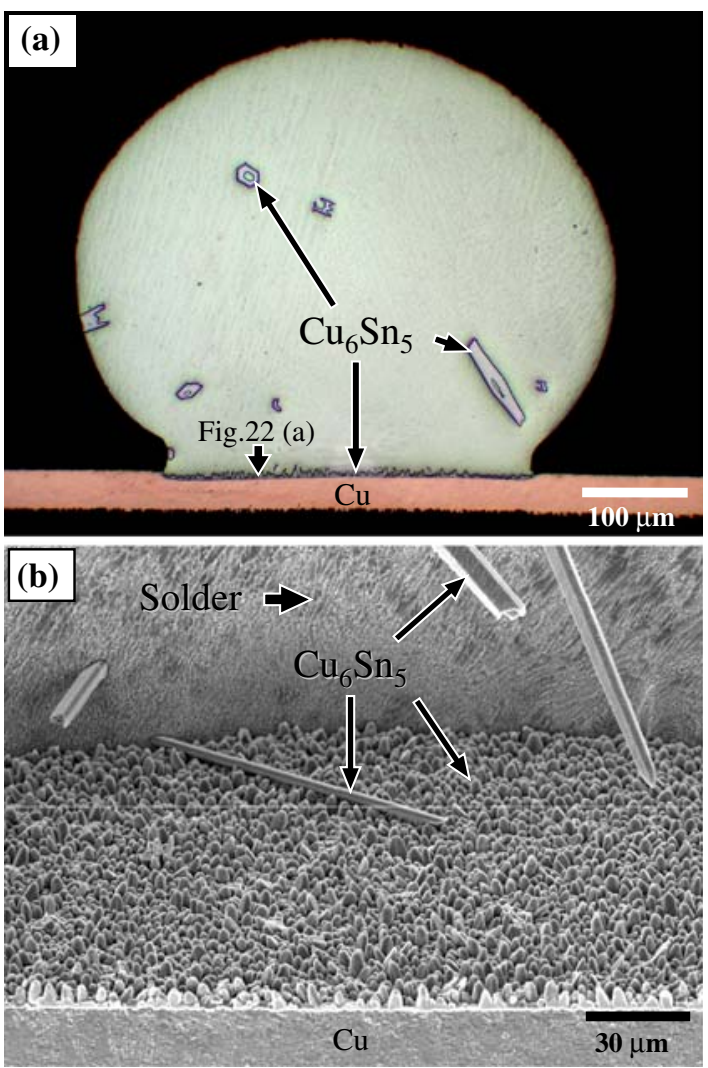

Fig. 23 (a) Micrograph showing the solder/Cu interface after the first reflow. The $\mathrm{Cu}$ atoms in those $\mathrm{Cu}_{6} \mathrm{Sn}_{5}$ needles inside the solder came from the dissolved $\mathrm{Cu}$ atoms when the solder was molten. (b) Long $\mathrm{Cu}_{6} \mathrm{Sn}_{5}$ needles described in (a). Part of the solder had been etched away

shifting of the equilibrium phase at the interface could cause the massive spalling of the intermetallic from the interface.

Lastly, the effect of cross-interaction of the $\mathrm{Cu}$ and Ni substrate across a solder joint was highlighted. This cross-interaction can occur during the reflow stage. Consequently, the sequence of assembly has an effect on the microstructure of the solder joints.

Acknowledgements This work was supported by the National Science Council of R.O.C. through grants NSC-94-2216-E-008001 and NSC-94-2214-E-008-005. The author (CRK) would like to thanks his students for their contributions to the study of soldering reactions (C. M. Liu, J. Y. Tsai, C. W. Chang, W. C. Luo, W. T. Chen, and L. C. Shiau).

\section{References}

1. A. Rahn (ed.), in The Basics of Soldering (John Wiely \& Sons, New York, 1993)

2. J.H. Lau (ed.), in Flip Chip Technology (McGraw Hill, New York, 1996)

3. K.N. Tu, K. Zeng, Mater. Sci. Eng. R34, 1 (2001)

4. W.G. Bader, Weld. J. Res. Suppl. 28, 551s (1969)
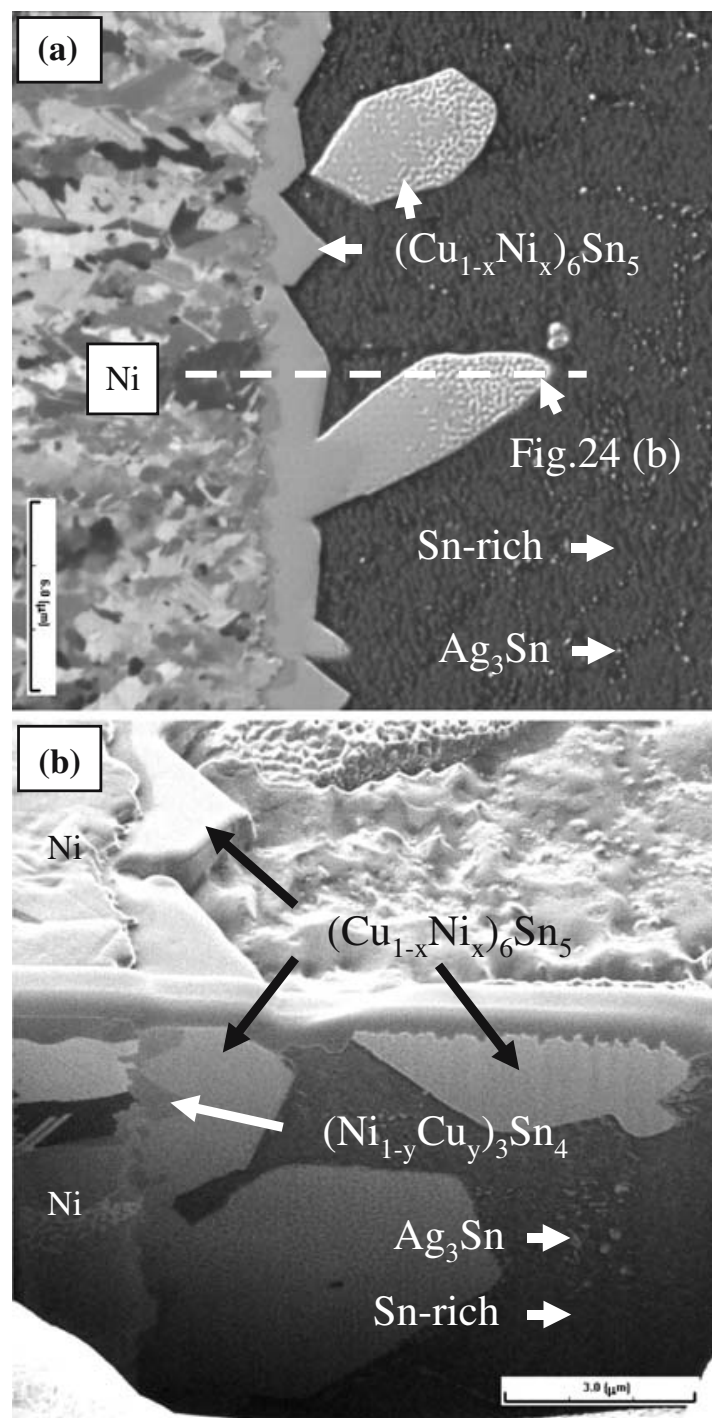

Fig. 24 (a) Plain view micrograph showing the Ni/solder interface in Fig. 22(e) after FIB polishing. (b) Cross-section view micrograph from the dash line in (a)

5. C.J. Thwaites, Electroplat. Met. Finish. 26, 10 (1973)

6. W.A. Mulholland, D.L. Willyard, Weld. J. Res. Suppl. 54, 466s (1974)

7. R. Duckett, M.L. Ackroyd, Electroplat. Met. Finish. 29, 13 (1976)

8. H. Heinzel, K.E. Saeger, Gold Bull. 9, 7 (1976)

9. D.M. Jacobson, G. Jumpston, Gold Bull. 22, 9 (1989)

10. P.A. Kramer, J. Glazer, J.W. Morris, Jr., Metall. Mater. Trans. 25A, 1249 (1994)

11. J. Glazer, Inter. Mater. Rev. 40, 65 (1995)

12. F.G. Yost, Gold Bull. 10, 94 (1977)

13. C.E. Ho, Y.M. Chen, C.R. Kao, J. Electron. Mater. 28, 1231 (1999)

14. C.E. Ho, S.Y. Tsai, C.R. Kao, IEEE Trans. Adv. Packag. 24 493 (2001)

15. Z. Huang, P.P. Conway, C. Liu, R.C. Thomson, J. Electron. Mater. 33, 1227 (2004)

16. J.W. Jang, P.G. Kim, K.N. Tu, D.R. Frear, P. Thomson, J. Appl. Phys. 85, 8456 (1999) 
Fig. 25 Glancing angle XRD pattern of the interface in Fig. 21(d) and (e). The crystal structures of the $\mathrm{Ni}_{3} \mathrm{Sn}_{4}$ compound [Fig. 21(d)] and the $\left(\mathrm{Cu}_{1-x} \mathrm{Ni}_{x}\right)_{6} \mathrm{Sn}_{5}$ compound [Fig. 21(e)] were positively identified

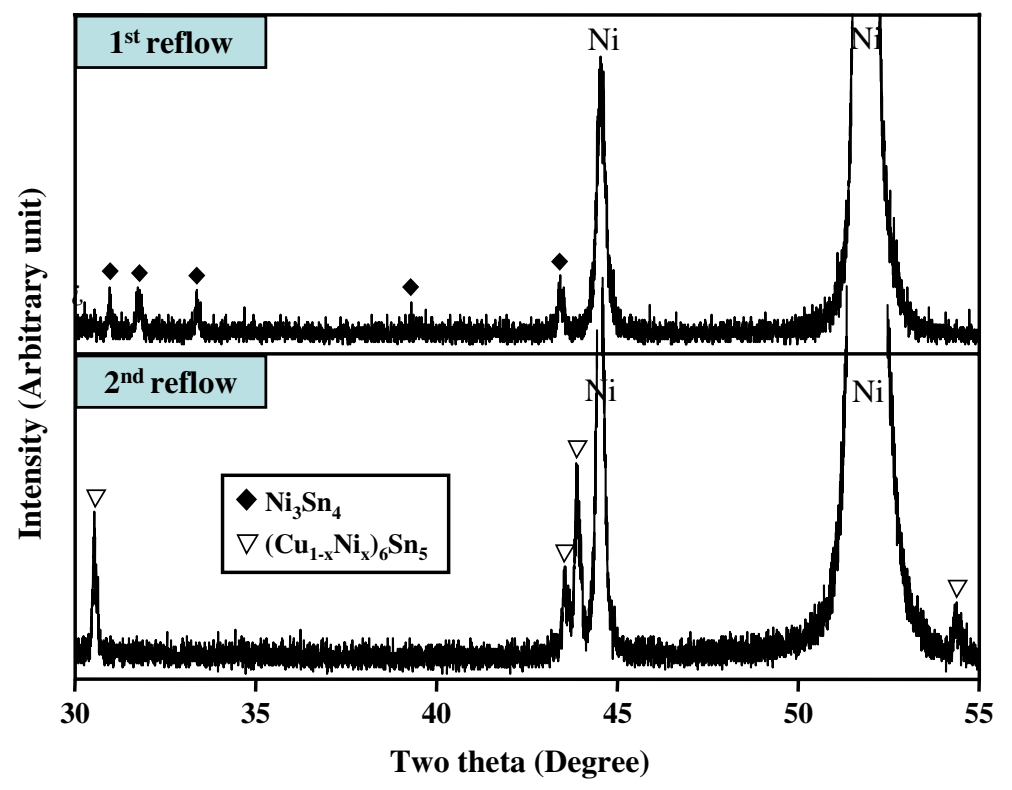

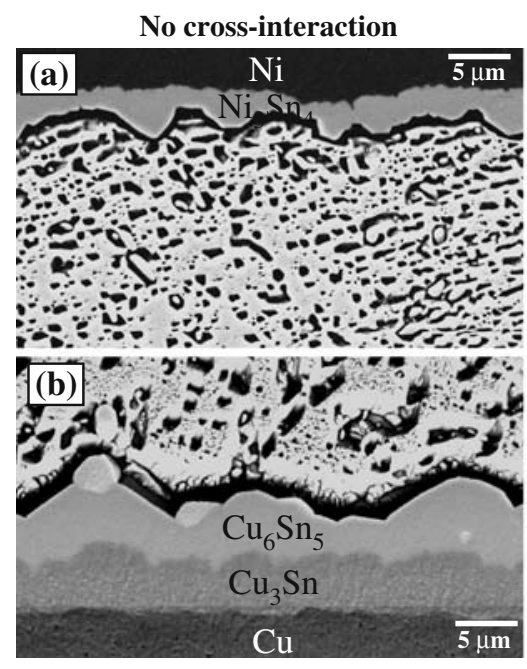
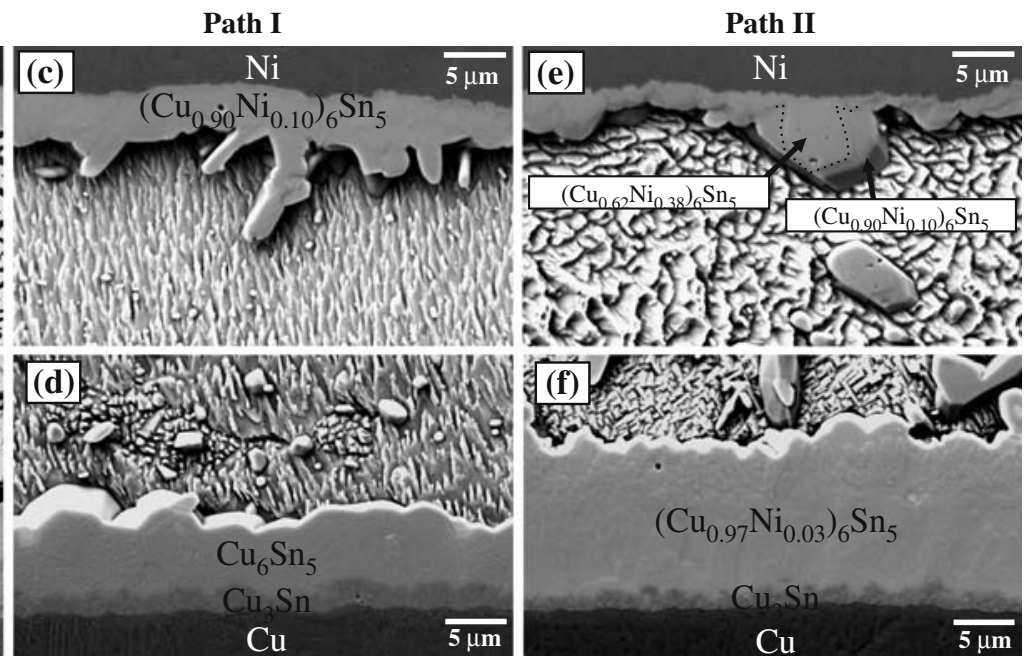

Fig. 26 Micrographs showing the microstructures of the interfaces in Fig. 22 after aging at $160^{\circ} \mathrm{C}$ for $1,000 \mathrm{~h}$. Each micrograph here corresponds to the after-aging microstructure of the interface that has the same label in Fig. 22

17. P. Liu, Z. Xu, J.K. Shang, Metall. Mater. Trans. 31A, 2857 (2000)

18. H. Matsuki, H. Ibuka, H. Saka, Sci. Technol. Adv. Mater. 3, 261 (2002)

19. K. Zeng, V. Vuorinen, J.K. Kivilahti, IEEE Trans. Electron. Packag. Manufact. 25, 162 (2002)

20. S.K. Kang, D.Y. Shih, K. Fogel, P. Lauro, M.J. Yim, G.G. Advocate, Jr., M. Griffin, C. Goldsmith, D.W. Henderson, T.A. Gosselin, D.E. King, J.J. Konrad, A. Sarkhel, K.J. Puttlitz, IEEE Trans. Electron. Packag. Manufact. 25, 155 (2002)

21. Y.D. Jeon, S. Nieland, A. Ostmann, H. Reichl, K.W. Paik, J. Electron. Mater. 32, 548 (2003)

22. N. Torazawa, S. Arai, Y. Takase, K. Sasaki, H. Saka, Mater. Trans. 44, 1438 (2003)

23. T. Hiramori, M. Ito, M. Yoshikawa, A. Hirose, K.F. Kobayashi, Mater. Trans. 44, 2375 (2003)
24. C.W. Hwang, K. Suganuma, M. Kiso, S. Hashimoto, J. Mater. Res. 18, 2540 (2003)

25. C.W. Hwang, K. Suganuma, M. Kiso, S. Hashimoto, J. Electron. Mater. 33, 1200 (2004)

26. M. He, Z. Chen, G. Qi, Acta Mater. 52, 2047 (2004)

27. J.W. Yoon, S.W. Kim, S.B. Jung, J. Alloys Compd. 385, 192 (2004)

28. Y.D. Jeon, K.W. Paik, A. Ostmann, H. Reichl, J. Electron. Mater. 34, 80 (2005)

29. T. Laurila, V. Vuorinen, J.K. Kivilahti, Mater. Sci. Eng. R49, 1 (2005)

30. T.T. Mattila, J.K. Kivilahti, J. Electron. Mater. 34, 969 (2005)

31. A. Kumar, M. He, Z. Chen, Surf. Coat. Tech. 198, 283 (2005)

32. S.T. Kao, J.G. Duh, J. Electron. Mater. 34, 1129 (2005)

33. J.W. Yoon, S.B. Jung, J. Alloys Compd. 396, 122 (2005) 
34. D.G. Kim, J.W. Kim, S.B. Jung, Mater. Sci. Eng. B 121, 204 (2005)

35. C.Y. Liu, K.N. Tu, T.T. Sheng, C.H. Tung, D.R. Frear, P. Elenius, J. Appl. Phys. 87, 750 (2000)

36. P.S. Teo, Y.W. Huang, C.H. Tung, M.R. Marks, T.B. Lim, in Proc. of 2000 IEEE Electron. Comp. Tech. Conf. (ECTC), p. 33

37. F. Zhang, M. Li, C.C. Chum, K.N. Tu, J. Mater. Res. 17, 2757 (2002)

38. F. Zhang, M. Li, C.C. Chum, Z.C. Shao, J. Electron. Mater. 32, 123 (2003)

39. M. Abtew, G. Selvaduray, Mater. Sci. Eng. R27, 95 (2000)

40. K. Suganuma, Curr. Opin. Solid State Mater. Sci. 5, 55 (2001)

41. K. Zeng, K.N. Tu, Mater. Sci. Eng. R38, 55 (2002)

42. K.N. Tu, A.M. Gusak, M. Li, J. Appl. Phys. 93, 1335 (2003)

43. C.M.L. Wu, D.Q. Yu, C.M.T. Law, L. Wang, Mater. Sci. Eng. R44, 1 (2004)

44. S.K. Kang, P.A. Lauro, D.-Y. Shih, D.W. Henderson, K.J. Puttlitz, IBM J. Res. \& Dev. 49, 607 (2005)

45. S. Ahat, M. Sheng, L. Luo, J. Electron. Mater. 30, 1317 (2001)

46. T.-C. Chiu, K. Zeng, R. Stierman, D. Edwards, K. Ano, in Proceedings of 2004 IEEE Electron. Comp. Tech. Conf. (ECTC), p. 1256

47. M. Date, T. Shoji, M. Fujiyoshi, K. Sato, K. N. Tu, Proceedings of 2004 IEEE Electron. Comp. Tech. Conf. (ECTC), p. 668

48. P.T. Vianco, J.A. Rejent, P.F. Hlava, J. Electron. Mater. 33, 991 (2004)

49. P. Borgesen, D. W. Henderson, Report of Universal Instruments (http://www.uci.com), (2004)

50. K. Zeng, R. Stierman, T.-C. Chiu, D. Edwards, K. Ano, K.N. Tu, J. Appl. Phys. 97, 024508 (2005)

51. Z. Mei, M. Ahmad, M. Hu, G. Ramakrishna, in Proceedings of 2005 IEEE Electron. Comp. Tech. Conf. (ECTC), p. 415

52. M. Oh, Doctor Dissertation, Lehigh University, (1994)

53. S.W. Chen, S.H. Wu, S.W. Lee, J. Electron. Mater. 32, 1188 (2003)

54. J.Y. Tsai, Y.C. Hu, C.M. Tsai, C.R. Kao, J. Electron. Mater. 32, 1203 (2003)

55. C.M. Chung, P.C. Shih, K.L. Lin, J. Electron. Mater. 33, 1 (2004)

56. L. Garner, S. Sane, D. Suh, T. Byrne, A. Dani, T. Martin, M. Mello, M. Patel, R. Williams, Intel Technol. J. 9, 297 (2005)

57. I.E. Anderson, J.L. Harringa, J. Electron. Mater. 35, 94 (2006)

58. T.B. Massalski (ed.), in Binary Alloy Phase Diagrams (ASM International, Metal Park, OH, 1990) p. 1481

59. P. Nash, A. Nash, Bull. Alloy Phase Diag. 6, 350 (1985)

60. E.K. Ohriner, Weld. J. Res. Suppl. 7, 191 (1987)

61. S. Bader, W. Gust, H. Hieber, Acta. Metall. Mater. 43, 329 (1995)

62. D. Gur, M. Bamberger, Acta Mater. 46, 4917 (1998)

63. J.A. van Beek, S.A. Stolk, F.J. J. van Loo, Z. Metallkde 73, 441 (1982)

64. C.M. Liu, M.S. Thesis, National Central University, Taiwan (2000)

65. K.-W. Moon, W.J. Boettinger, U.R. Kattner, F.S. Biancaniello, C.A. Handwerker, J. Electron. Mater. 29, 1122 (2000)

66. NEMI (National Electronics Manufacturing Initiative)Workshop on Modeling and Data Needs for Lead-Free solders, (New Orleans, LA, February 15th 2001)

67. Soldertec-ITRI, Lead-free alloys-the way forward, October 1999 (http://www.lead-free.org)
68. IDEALS (International Dental Ethics and Law Society), Improved design life and environmentally aware manufacturing of electronics assemblies by lead-free soldering, Brite-Euram contract BRPR-CT96-0140, project number BE95-1994 (1994-1998)

69. JEITA (Japan Electronics and Information Technology Industries Association), Lead-Free Roadmap 2002, v 2.1, (2002)

70. K.F. Seeling, D.G. Lockard, United States Patent, Patent No. 5352407, (Oct 1994)

71. IPC Roadmap, Assembly of Lead-Free Electronics, 4th draft, IPC, (Northbrook, IL, June 2000)

72. L.S. Bai, Taiwan Printed Circuit Association (TPCA) Magazine 31, 21 (2006)

73. C.E. Ho, Y.L. Lin, C.R. Kao, Chem. Mater. 14, 949 (2002)

74. J.W. Jang, D.R. Frear, T.Y. Lee, K.N. Tu, J. Appl. Phys. 88, $6359(2000)$

75. C.E. Ho, R.Y. Tsai, Y.L. Lin, C.R. Kao, J. Electron. Mater. 31, 584 (2002)

76. S.M. Hong, C.S. Kang, J.P. Jung, IEEE Trans. Adv. Packag. 27, 90 (2004)

77. G.Y. Jang, J.G. Duh, J. Electron. Mater. 34, 68 (2005)

78. C.M. Liu, C.E. Ho, W.T. Chen, C.R. Kao, J. Electron. Mater. 30, 1152 (2001)

79. M. Li, K.Y. Lee, D.R. Olsen, W.T. Chen, B.T. C. Tan, S. Mhaisalkar, IEEE Trans. Electron. Packag. 25, 185 (2002)

80. S.K. Kang, W.K. Choi, M.J. Yim, D.Y. Shih, J. Electron. Mater. 31, 1292 (2002)

81. L.C. Shiau, C.E. Ho, C.R. Kao, Solder. Surf. Mount Tech. 14/3, 25 (2002)

82. M.O. Alam, Y.C. Chan, K.N. Tu, Chem. Master. 15, 4340 (2003)

83. K.Y. Lee, M. Li, J. Electron. Mater. 32, 906 (2003)

84. C.B. Lee, J.W. Yoon, S.J. Suh, S.B. Jung, C.W. Yang, C.C. Shur, Y.E. Shin, J. Mater. Sci.: Mater. Electron. 14, 487 (2003)

85. A. Sharif, M.N. Islam, Y.C. Chan, Mater. Sci. Eng. B 113, 184 (2004)

86. D.Q. Yu, C.M. L. Wu, D.P. He, N. Zhao, L. Wang, J.K.L. Lai, J. Mater. Res. 20, 2205 (2005)

87. W.T. Chen, C.E. Ho, C.R. Kao, J. Mater. Res. 17, 263 (2002)

88. W.C. Luo, C.E. Ho, J.Y. Tsai, Y.L. Lin, C.R. Kao, Mater. Sci. Eng. A 396, 385 (2005)

89. C.E. Ho, W.C. Luo, S.C. Yang, C.R. Kao, in Proceedings of IMAPS Taiwan 2005 International Technical Symposium (Taipei, June 2005), p. 98

90. C.E. Ho, Y.W. Lin, S.C. Yang, C.R. Kao, in Proceedings of the 10th International Symposium on Advanced Packaging Materials: Processes, Properties and Interface, IEEE/ CPMT (Irvine, March 2005), p. 39

91. C.E. Ho, Y.W. Lin, S.C. Yang, C.R. Kao, D. S. Jiang, J. Electron. Mater. 35, 1017 (2006)

92. M.O. Alam, Y.C. Chan, K.N. Tu, J.K. Kivilahti, Chem. Mater. 17, 2223 (2005)

93. K.S. Kim, S.H. Huh, K. Suganuma, J. Alloys Compd. 352, $226(2003)$

94. J.S. Ha, T.S. Oh, K.N. Tu, J. Mater. Res. 18, 2109 (2003)

95. C.H. Wang, S.W. Chen, Acta Mater. 54, 247 (2006)

96. S.K. Kang, W.K. Choi, D.Y. Shih, P. Lauro, D.W. Henderson, T. Gosselin, D.N. Leonard, in Proceedings of 2002 IEEE Electron. Comp. Tech. Conf. (ECTC), p. 146

97. Y. Zheng, C. Hillman, P. McCluskey, in Proceedings of 2002 IEEE Electron. Comp. Tech. Conf. (ECTC), p. 1226

98. M.D. Cheng, S.Y. Chang, S.F. Yen, T.H. Chuang, J. Electron. Mater. 33, 171 (2004) 
99. J.H. L. Pang, T.H. Low, B.S. Xiong, X. Luhua, C.C. Neo, Thin Sol. Films, 462-463, 370 (2004)

100. J.W. Yoon, S.W. Kim, J.M. Koo, D.G. Kim, S.B. Jung, J. Electron. Mater. 33, 1190 (2004)

101. J.W. Yoon, S.W. Kim, S.B. Jung, J. Alloys Compd. 391, 82 (2005)

102. C.B. Lee, S.B. Jung, Y.E. Shin, C.C. Shur, Mater. Trans. 43, 1858 (2002)

103. A. Zribi, A. Clark, L. Zavalij, P. Borgesen, E.J. Cotts, J. Electron. Mater. 30, 1157 (2001)

104. G. Ghosh, Acta Mater. 49, 2609 (2001)

105. G. Ghosh, J. Electron. Mater. 33, 229 (2004)

106. C.E. Ho, Doctor Dissertation, National Central University, Taiwan, (2002)

107. C.E. Ho, L.C. Shiau, C.R. Kao, J. Electron. Mater. 31, 1264 (2002)

108. L.P. Lehman, S.N. Athavale, T.Z. Fullem, A.C. Giamis, R.K. Kinyanjui, M. Lowenstein, K. Mather, R. Patel, D. Rae, J.Wang, Y. Xing, L. Zavalij, P. Borgesen, E.J. Cotts, J. Electron. Mater. 33, 1429 (2004)

109. D.W. Henderson, T. Gosselin, A. Sarkhel, S.K. Kang, W.K. Choi, D.Y. Shih, C. Goldsmith, K. Puttlitz, J. Mater. Res. 17, 2775 (2002)

110. S.K. Kang, W.K. Choi, D.Y. Shih, D.W. Henderson, T. Gosselin, A. Sarkhel, C. Goldsmith, K. Puttlitz, in
Proceedings of 2003 IEEE Electron. Comp. Tech. Conf. (ECTC), p. 64

111. S.K. Kang, W.K. Choi, D.Y. Shih, D.W. Henderson, T. Gosselin, A. Sarkhel, C. Goldsmith, K. Puttlitz, J. Minerals Metals Mater. Soc. 55, 61 (2003)

112. S. Terashima, Y. Kariya, T. Hosoi, M. Tanaka, J. Electron. Mater. 32, 1527 (2003)

113. C.H. Lin, S.W. Chen, C.H. Wang, J. Electron. Mater. 31, 907 (2002)

114. C.Y. Li, J.G. Duh, J. Mater. Res. 20, 3118 (2005)

115. P. Oberndorff, Doctoral Dissertation, Technical University of Eindhoven, (2001)

116. G.Z. Pan, A.A. Liu, H.K. Kim, K.N. Tu, P.A. Totta, Appl. Phys. Lett. 71, 2946 (1997)

117. C.R. Kao, C.E. Ho, L.C. Shiau, Solder Point with Low Speed of Consuming Nickel, R.O.C. patent, patent No. 181410, (2003)

118. S.J. Wang, C.Y. Liu, J. Electron. Mater. 32, 1303 (2003)

119. T.L. Shao, T.S. Chen, Y.M. Huang, C. Chen, J. Mater. Res. 19, 3654 (2004)

120. C.M. Tsai, W.C. Luo, C.W. Chang, Y.C. Shieh, C.R. Kao, J. Electron. Mater. 33, 1424 (2004) 